Trabajos y Comunicaciones, 2da. Época, No 48, e066, julio-diciembre 2018. ISSN 2346-8971

Universidad Nacional de La Plata.

Facultad de Humanidades y Ciencias de la Educación.

Departamento de Historia

\title{
Conflictividad estudiantil, radicalización política y reformismo universitario durante las décadas del sesenta y setenta. El caso del movimiento estudiantil de la ciudad de La Plata 1969-1972
}

\author{
Agustín Nava * \\ * Universidad Nacional de La Plata, Argentina \\ agustinnava82@hotmail.com
}

Cita sugerida: Nava, A. (2018). Conflictividad estudiantil, radicalización política y reformismo universitario durante las décadas del sesenta y setenta. El caso del movimiento estudiantil de la ciudad de La Plata 1969-1972. Trabajos y Comunicaciones (48), e066. https://doi.org/10.24215/23468971e066

Recibido: 5 de marzo de 2018 | Aceptado: 1 de junio de 2018 I Publicado: 27 de julio de 2018

Esta obra está bajo licencia Creative Commons Atribución-NoComercial-CompartirIgual 4.0 Internacional http://creativecommons.org/licenses/by-nc-sa/4.0/deed.es AR 


\section{Conflictividad estudiantil, radicalización política y reformismo universitario durante las décadas del sesenta y setenta. El caso del movimiento estudiantil de la ciudad de La} Plata 1969-1972

Student conflict, political radicalization and university reformism during the sixties and seventies. The case of the student movement of the city of La Plata 1969-1972.

Agustin Nava

Universidad Nacional de La Plata, Argentina

agustinnava82@hotmail.com

\section{RESUMEN:}

El presente trabajo se inscribe dentro del campo de estudios sobre la historia del movimiento estudiantil reformista durante los años 60 y 70 en la Argentina y tiene como propósito más específico la elaboración de un mapa de la conflictividad del movimiento estudiantil desarrollada entre los años 1969-1972, en una región en particular: la ciudad de La Plata. Dicho mapa de la conflictividad se realizará por medio de un estudio cuantitativo, confeccionado a partir fuentes hemerográficas. Las variables que se analizaran serán las siguientes: la intensidad y masividad que evidenciaron los conflictos; los distintos sectores y actores que al interior del movimiento estudiantil presentaron un mayor protagonismo; los reclamos y demandas que motorizaron las luchas; las formas y características que adquirieron las acciones motorizadas por los estudiantes, como así también los vínculos y alianzas que establecieron con el movimiento obrero y con otros sectores sociales. Las tendencias divisadas en la conflictividad estudiantil serán puestas en tensión con las encontradas para el caso en particular del movimiento obrero del Gran La Plata, que hemos analizado en otros trabajos, lo que nos permitirá no solo contrastar sino también apreciar con mayor precisión las particularidades que presentó la conflictividad del movimiento estudiantil reformista platense. La finalidad de dicho análisis es poder tanto complejizar y matizar algunas lecturas e interpretaciones generales sobre el periodo en particular, como profundizar sobre varias temáticas y dimensiones que hacen a las características y dinámica que presentó el movimiento estudiantil durante las décadas del sesenta y setenta.

Palabras Clave: Conflictividad estudiantil; Movimiento reformista; Movimiento obrero; La Plata.

\section{Abstract:}

This paper is part of the field of studies on the history of the reformist student movement during the $60 \mathrm{~s}$ and $70 \mathrm{~s}$ in Argentina and has as its most specific purpose the development of a map of the conflictivity of the student movement developed between the years 1969-1972, in a particular region: the city of La Plata. The map of the conflict will be carried out through a quantitative study, made from newspaper sources. The variables that will be analyzed will be the following: the intensity and massiveness evidenced by the conflicts; the different sectors of the student movement that presented a greater role; the demands that motorized the struggles; the forms and characteristics that student conflicts acquired, as well as the links they established with the workers' movement and with other social sectors. The tendencies of the student conflict will be put in tension with those of the labor movement of the Gran La Plata, which we have analyzed in other works, which will allow us not only to contrast but also to appreciate more precisely the particularities presented by the conflictivity of the reformist student movement platense. The purpose of this analysis is to be able to make complex certain readings and general interpretations about the period in particular, as well as to deepen on topics and dimensions referring to the characteristics and dynamics of the Student movement in general.

KEYWORDS: Student conflict; Reformism; Working Movement; La Plata.

\section{INTRODUCCIÓN}

El objetivo que se propone este trabajo es presentar, por medio de un estudio cuantitativo, el mapa de la conflictividad del movimiento estudiantil platense bajo el periodo 1969-1972, es decir durante la etapa que podríamos conceptualizar como el “ocaso" de la autodenominada "Revolución Argentina”. Dicho mapa nos 
permitirá acceder a un primer abordaje de las principales pautas, tendencias y características que presentaron las luchas del movimiento estudiantil de la ciudad de La Plata. Movimiento que, en nuestro periodo de análisis, presentaba como identidad política predominante al reformismo universitario.

En general, suele haber cierto consenso en la literatura historiográfica y sociológica respecto a las transformaciones que sufrió la dinámica de la protesta social a partir del golpe de Estado de 1966 y más en particular con los levantamientos de masas que se suceden en la Argentina desde 1969. Lo distintivo de este nuevo ciclo de protesta social residiría en que el movimiento de oposición política a la dictadura derivó en un fenómeno de radicalización política y social, cuyos principales protagonistas fueron el movimiento obrero y el movimiento estudiantil (Tortti, 2006, Bonavena et al, 1998).

Si bien desde nuestro punto de vista acordamos con esta caracterización general del periodo, consideramos, sin embargo, que tanto la emergencia del movimiento de protesta social y de radicalización política, como el posterior desarrollo y dinámica que tuvo el mismo, no suelen estar lo suficientemente profundizados, quedando muchas veces sin problematizar las situaciones locales específicas, las líneas divergentes, la fluidez de las distintas estrategias, trayectorias e identidades políticas, y la diversidad de enfrentamientos inter e intraclase. En este sentido, este trabajo intenta realizar un aporte en la tarea de precisar cuáles fueron los alcances, ritmos y modalidades concretas que dichos procesos tuvieron, abordando el mismo a partir de un estudio de caso, el cual se enfocará particularmente en la dinámica del proceso de luchas que llevó adelante el movimiento estudiantil de la UNLP (Universidad Nacional de La Plata) y del vínculo que el mismo estableció con otros sectores sociales. Tengamos en cuenta que, desde sus comienzos, la consigna "unidad obrero- estudiantil" fue uno de los elementos centrales del acervo político e ideológico del movimiento estudiantil reformista (Pis Diez, 2017: 100).

Más específicamente el propósito de este artículo es delimitar el ciclo de luchas del movimiento estudiantil tanto en función de la intensidad y masividad que evidenciaron los conflictos, los distintos sectores y actores que al interior del movimiento estudiantil presentaron un mayor protagonismo, como los reclamos y demandas que motorizaron las luchas. Asimismo, desarrollamos las formas y características que adquirieron las acciones motorizadas por los estudiantes, como también los vínculos y alianzas que establecieron con el movimiento obrero y con otros sectores sociales. Estas tendencias serán puestas en tensión con las divisadas para el caso en particular del movimiento obrero del Gran La Plata, que hemos analizado en otros trabajos, lo que nos permitirá no solo contrastar sino también apreciar con mayor precisión las particularidades que presentó la conflictividad del movimiento estudiantil. ${ }^{1}$

Retomando la propuesta desarrollada por Izaguirre y Aristizabal (2002), en un trabajo anterior (Nava y Romá, 2011) hemos especificados el procedimiento, las decisiones y problemas teóricos-metodológicos que se derivan del análisis cuantitativo de la protesta social y que lo fundamentan. En particular, el procedimiento utilizado para la elaboración de la base de datos estuvo basado exclusivamente en la recolección y codificación de material periodístico, en particular del diario El Día de la ciudad de La Plata. ${ }^{2}$ El total de conflictos del movimiento estudiantil que hemos registrado para el periodo $1969-1972$ es de 1050 hechos. ${ }^{3}$ De dicho dato la primer observación que se desprende es la participación disímil, en términos meramente cuantitativos, que presenta el movimiento estudiantil en el ciclo de protesta social desarrollado en el marco regional del Gran La Plata, en comparación con el caso del movimiento obrero regional, que en el mismo lapso de tiempo lleva a cabo casi el doble de acciones (2045) que el movimiento estudiantil. Esta comparación meramente cuantitativa adquirirá otro relieve cuando incorporemos al análisis otras variables. De todos modos, antes de analizar específicamente el proceso de lucha del movimiento estudiantil, describiremos el panorama universitario más general en el que estaban insertos.

Tengamos en cuenta que el sujeto en el que nos vamos a enfocar ya se encontraba fuertemente movilizado y politizado en la etapa previa a la que nosotros analizaremos. ${ }^{4}$ Asimismo no solo fue un actor central en el mapa de la conflictividad social del periodo, sino que además tenía un ámbito natural de actuación, la Universidad, que presentaba una centralidad no menor en la dinámica política y social de la propia 
ciudad de La Plata. Ya desde las primeras décadas del siglo XX La Plata era reconocida por su status de ciudad universitaria. Considerada estadísticamente, la población estudiantil de La Plata era una de las más significativas del país, ya que con sus casi $29000^{5}$ estudiantes representaba el 5.13\% de la población de este conglomerado (Millán, 2011), además de ser la UNLP el establecimiento con mayor cantidad de estudiantes después de la Universidad de Buenos Aires (UBA). Por añadidura, la cuestión universitaria representó un aspecto fundamental del proyecto político y social de la dictadura militar instaurada en 1966.

\section{La “Revolución Argentina” y la cuestión Universitaria}

Como decíamos, la Universidad no solo tenía una importancia per se en el ámbito político y social platense, sino que además para el proceso abierto en 1966, la cuestión universitaria en general también ocupaba un lugar central en su proyecto político y social. En gran parte como consecuencia de un acuerdo generalizado entre sus perpetradores de que las distintas Universidades Nacionales se habían transformado en "ciudadelas de la indisciplina y la subversión" (Altamirano, 2001: 82). Dicha lectura se hacía presente en un contexto general, signado a mediados de la década del sesenta, tanto por la expansión de la matrícula universitaria ${ }^{6}$ como por una creciente politización del movimiento estudiantil. Como señala Mignone, las Universidades Nacionales eran consideradas por los nuevos gobernantes como “...un reducto del protagonismo estudiantil, la izquierda marxista y la desintegración social” (Mignone, 1998: 44). Independientemente del grado de verosimilitud de esta lectura ${ }^{7}$, lo cierto es que en parte como consecuencia de su capacidad crítica y por su influencia en el medio cultural y político, las universidades podían convertirse en un obstáculo de consideración para el proyecto que se proponía implementar el régimen militar.

En este sentido, uno de los objetivos primordiales que se propuso la dictadura de Onganía fue la necesidad de colocar nuevamente a las universidades bajo la egida del poder político, limitando la libertad y autonomía académica de la que habían gozado hasta ese momento, tratando de imponerle a las mismas su impronta autoritaria y disciplinadora. Consecuentemente con dichos objetivos, el Gobierno Nacional sancionó el decreto ley 16912, el 29 de julio de 1966 (es decir, un mes después de producido el golpe), por el cual se eliminaba el gobierno tripartito y con ella la participación estudiantil en el cogobierno universitario. Tengamos en cuenta que la participación estudiantil en asambleas y consejos no solo era considerada una conquista inalienable para el movimiento estudiantil reformista, sino también una tradición con casi medio siglo en la Argentina. Por añadidura, a las instancias de representación estudiantil se les vedaba la actividad política, bajo la amenaza de disolución de las mismas. ${ }^{8}$ La norma, además, anulaba los consejos superiores y transformaba a los rectores y decanos en interventores subordinados a las autoridades del Ministerio de Educación, en la medida en que pasaban a ser designados por el propio Poder Ejecutivo, debiendo cumplir funciones meramente administrativas.

De todas formas, en un primer momento, e independientemente de esta sesgo intervencionista y represivo (fundamentalmente ante las manifestaciones de protestas que se sucedieron en diferentes universidades del país), el gobierno de Onganía no tenía un proyecto más orgánico y coherente para las universidades. Recién a principios de 1967 comenzaron a discutirse, en el marco de un "Consejo Asesor" creado al efecto, los lineamientos de una nueva ley que regiría la vida académica y que finalmente sería sancionada dicho año, bajo el número 17245 ("Ley orgánicas de las Universidades Nacionales"). Por medio de esta norma se establecía un régimen orgánico que regiría en común para todas las Universidades Nacionales y a partir del cual cada una de ellas debía establecer sus estatutos particulares. Como sostiene Natalia Vega la ley "restituía el exclusivo gobierno de los profesores y, además, contenía regulaciones profundamente elitistas y disciplinadoras" (Vega, 2014: 03). ${ }^{9}$ Entre ellas se podrían citar las iniciativas tendientes a eliminar todo tipo de actividad política en las casas de altos estudios y el establecimiento de un nuevo régimen de cursadas y mecanismos de ingreso 
restrictivos, ${ }^{10}$ aspectos estos últimos que serán centrales, como veremos más adelante, a la hora de dar cuenta de la dinámica de la conflictividad del movimiento estudiantil.

Cabe señalar, de todos modos, que si bien la política universitaria respondía a estas directrices en el plano nacional, en verdad tuvo un criterio de aplicación que presentó disimilitudes en función de las distintas universidades que componían el mapa universitario de la Argentina. El golpe militar de 1966 no presentó un impacto similar en las diversas unidades académicas del país. Las directrices emanadas en el plano nacional referidas a la cuestión universitaria no tuvieron, entonces, una traducción homogénea de universidad a universidad; al punto tal que, como sugiere Buchbinder, se podría sostener que los avances del gobierno militar en construir un nuevo régimen universitario no fueron muy exitosos. El caso platense sería bastante expresivo de esta tendencia. Suasnábar señala que "la casi inexistencia de renuncias, ${ }^{11}$ la cautela de los interventores y la tolerancia con la que éstos manejaron la UNLP” (Suasnábar, 2004: 66), determina en parte que la dinámica de esta casa de altos estudios no se ajuste de manera lineal a la imagen de "ruptura total", representación más asociada a los sucesos que tuvieron lugar en la UBA.

Por añadidura, el ciclo de protesta estudiantil que se inicia en todo el país a partir de 1969 marcará de manera más palmaria el fracaso del proyecto más orgánico de reconfiguración del mapa universitario, que se había propuesto concretar el régimen miliar instaurado en 1966. De manera que, en parte en respuesta a este ciclo, en las altas esferas de la política nacional bajo la presidencia de Lanusse se ensayará una táctica participacionista, con la cual se intentaba desarticular el ascenso de la protesta social y que tuvo su correspondencia también en al ámbito universitario, materializada a través de dos tipos de iniciativas. En primer lugar, como señala Bonavena (2014), el gobierno de Lanusse procuró dotar a las universidades de nuevos funcionarios que tuvieran un perfil más "dialoguista" y que, por ello, pudieran establecer puntos de encuentro con algunos de los sectores del movimiento estudiantil y de los no docentes, buscando así aislar a los sectores más radicalizados. El diagnóstico elaborado por algunos cuadros universitarios implicaba que una de las formas en la que podía solucionarse lo que era considerado como una "desmedida" conflictividad estudiantil y laboral, era institucionalizar por canales "normales" y "razonables" (tales como la participación en asambleas y consejos) los reclamos de los distintos actores de la universidad. La otra táctica utilizada por el nuevo gobierno para apaciguar la movilización y politización que se desarrollaba en los ámbitos universitarios fue la diversificación (fundamentalmente en términos territoriales) del sistema universitario y la creación de nuevas universidades, en lo que se conoció como el "plan Taquini". Dicho plan buscaba "compatibilizar el proceso de expansión de la matrícula universitaria, la conformación de una Universidad Científica, las necesidades derivadas del desarrollo regional y la despolitización” (Buchbinder, 2010: 199).

Esta argucia participacionista tiene su correlato en el ámbito universitario local, aunque podríamos sostener que se adelanta a la ensayada en el plano político nacional. A principios de 1970, y en un contexto signado por el crecimiento de la intensidad y combatividad de la protesta estudiantil en todo el país (que si bien tuvo su epicentro en Córdoba, se extendió rápidamente a la Capital Federal, Rosario, La Plata, etc) la intervención universitaria se vio obligada a retroceder en algunos planos. A principios de 1970 el propio presidente del CRUN (Consejo de Rectores de las Universidades Nacionales), Julio Herrera, declara que en su opinión una de las formas de evitar las “explosiones de violencia” (El Día, 26/02/1970), consistía en conceder una mayor participación estudiantil en la vida universitaria, lograr la normalización institucional de las casas de altos estudios y reexaminar los cursos de ingreso en algunas universidades. Al mismo tiempo, el rector de la UNLP, Roque Gatti, dictaba una resolución, que igualmente no dejaba de ser lo suficientemente ambigua, mediante la cual establecía que los cursos o pruebas de ingreso que se hayan realizado o que se estaban por realizar "no tienen carácter limitativo ni eliminatorio" (El Día, 27/02/1970), al tiempo que establecía que era responsabilidad de los decanos de cada facultad arbitrar los medios necesarios para lograr tal fin. ${ }^{12}$ Sin embargo, la situación en la UNLP no es homogénea, ya que esta actitud del rectorado de delegarle la responsabilidad a los decanos permite que en ciertas facultades la limitación sea más evidente que en otros. 
El desarrollo de este debate se encuentra cruzado además por un conflicto entre los rectores de las distintas universidades nacionales y el Poder Ejecutivo Nacional respecto a la falta de presupuesto de la que adolecían las universidades, que las obligaban a desenvolverse con recursos insuficientes. Dicha situación se volvió particularmente apremiante en 1971, al decidir el gobierno nacional que se repitieran los presupuestos de 1970 para el ejercicio del año siguiente. Este conflicto en particular tenía la virtud de aglutinar y unificar el posicionamiento de los todos los claustros universitarios. En el caso de la UNLP los inconvenientes generados por esta situación resultaron ser bastante apremiantes, al punto tal de que, en varias ocasiones a lo largo de 1971, Roque Gatti manifestara públicamente que debido a la insuficiencia de recursos, el gobierno nacional debía destinar por lo menos 1200 millones de pesos moneda nacional para que no se viese afectado el normal desenvolvimiento del ciclo lectivo (El Día, 06/05/1971). ${ }^{13}$ El problema de la insuficiencia presupuestaria cruzará de manera oblicua la dinámica sindical y política de la UNLP. En la medida en que esta "insuficiencia de recursos" discurría paralela a un crecimiento sostenido de la matrícula universitaria, lo que derivará en que las problemáticas referidas a la expansión del sistema universitario y la términos del ingreso y egreso al mismo se conviertan en ejes centrales de discusión, debate y movilización. ${ }^{14}$

\section{ASCENSOS Y DINÁMICAS DEL CICLO DE PROTESTA DEL MOVIMIENTO ESTUDIANTIL}

Como ya señalamos uno de los primeros aspectos que nos interesa determinar se refiere a cuál fue la dinámica que adquirió el ciclo de luchas que llevó adelante el movimiento estudiantil en nuestra región de estudio, en función en primer lugar de la intensidad y masividad que evidenciaron los conflictos. Si nos atenemos a un criterio de periodización anual, lo que se puede divisar, en términos generales, es una tendencia de la conflictividad estudiantil similar a la que se puede encontrar para el caso de la clase obrera tanto regional como nacional. Como se puede observar en la figura I, las luchas del movimiento estudiantil evidencian una tendencia creciente a partir de 1969, acompañando en parte la intensificación del proceso de protesta social y radicalización política que tenía lugar en la Argentina. El momento de mayor intensidad de la conflictividad estudiantil platense se alcanzará hacía el año 1971, delineándose así una curva con forma de U invertida, ya que para el año 1972, en un marco signado por la salida política ensayada por el general Lanusse, las luchas acusaran una sensible disminución. ${ }^{15}$

A primera vista el año 1969 parece representar, entonces, un claro punto de inflexión en el ciclo de conflictividad estudiantil, aunque si analizamos de manera más detenida y en términos comparativos, podemos observar que la curva de la conflictividad no es tan pronunciada como en el caso del movimiento obrero (véase figura II). Por el contrario, la conflictividad del movimiento estudiantil se mantuvo más bien de manera constante a lo largo de todo nuestro periodo de análisis, siendo igualmente el año 1971 un momento de mayor conflictividad con respecto a los demás. 


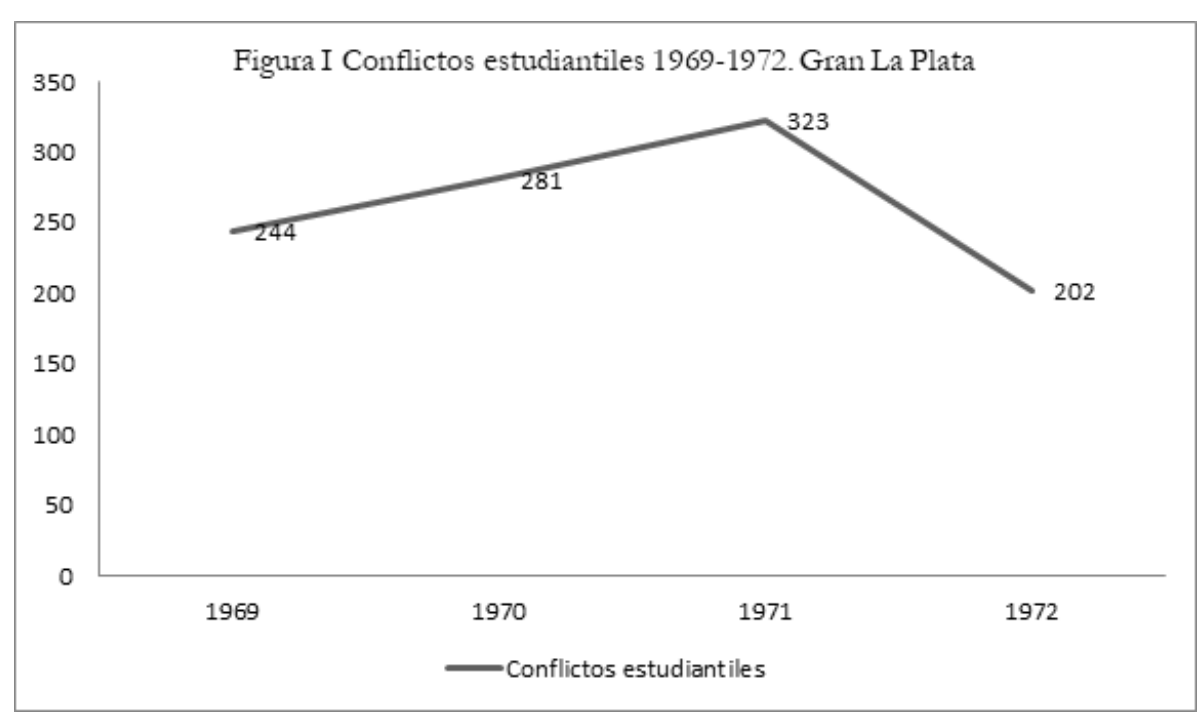

Fuente: elaboración propia en base a información periodística extraída del diario "El Día".

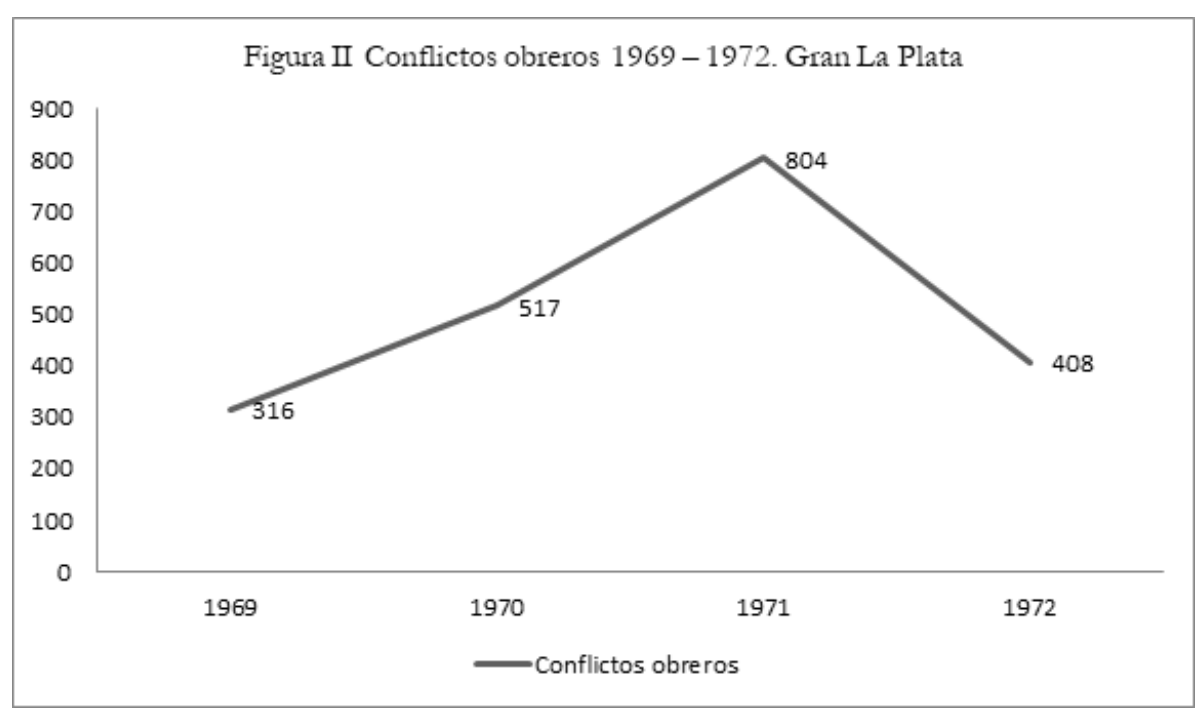

Fuente: elaboración propia en base a información periodística extraída del diario "El Día".

Más allá de esta dinámica a largo plazo, las luchas estudiantiles van a presentar la particularidad de acusar un comportamiento más bien cíclico y estacional, marcado en primer lugar, obviamente, por el calendario académico. Tendencia claramente delimitable si nos enfocamos en la periodicidad mensual de los conflictos. De la observación de la figura III se desprende que en los momentos de receso de la actividad académica (es decir durante los meses de diciembre, enero y julio) la dinámica del movimiento estudiantil se resiente de manera paralela a la paralización de las clases. Invariablemente los meses de febrero fueron momentos de gran y sostenida conflictividad, hecho que estaría estrechamente asociado con la centralidad que tuvieron las movilizaciones contra el carácter limitacionista que se juzgaba tenían los cursos de ingreso que se desarrollaban durante los primeros meses del año. ${ }^{16}$

Pero, por otro lado, además de estar marcada por la actividad académica, el ritmo de la dinámica de las luchas estudiantiles parece estar determinado más por acontecimientos políticos coyunturales. Si observamos la figura III, se pueden percibir en este caso cuatro grandes picos de conflictividad mensual comprendidos durante los años 1969-1970-1971, que sugerentemente se producen durante la misma época del año: en particular durante los meses de mayo y junio. El primero de aquellos picos mencionados tiene lugar durante los meses de mayo-junio de 1969, con un total de 50 y 46 conflictos mensuales respectivamente. 


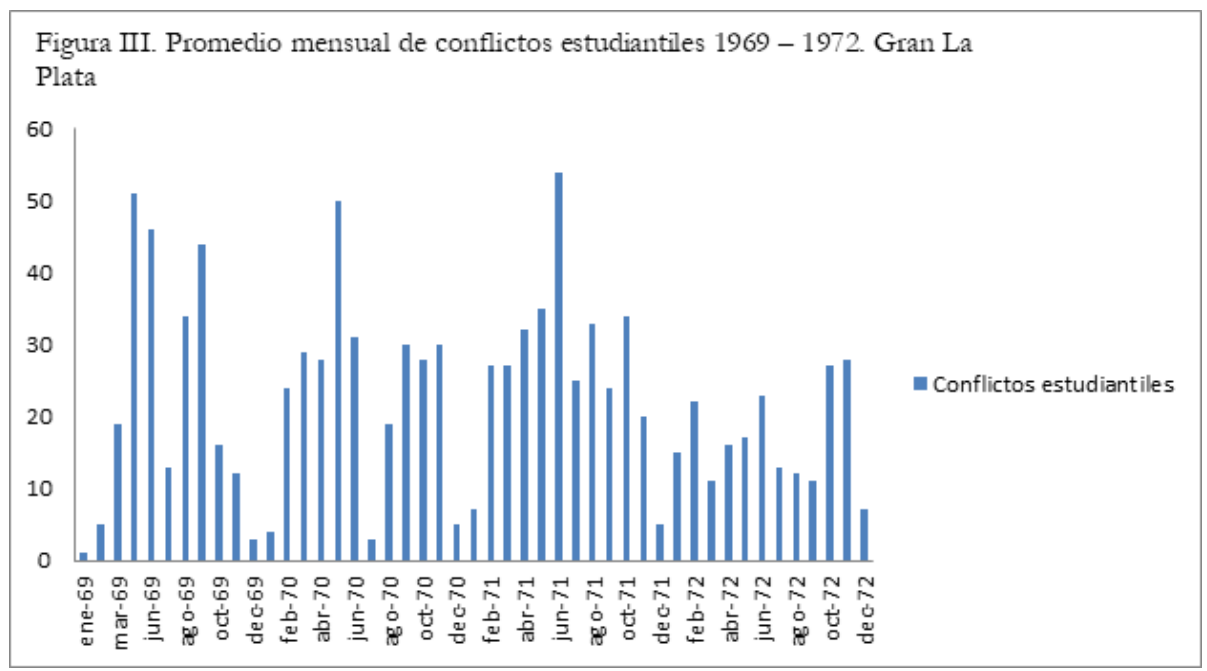

Fuente: elaboración propia en base a información periodística extraída del diario "El Día".

Dicho comportamiento responde, en nuestra opinión, a la activación e intensificación de las luchas del movimiento estudiantil en el plano nacional como consecuencia de los sucesos que estaban teniendo lugar en Corrientes, Rosario y Córdoba ${ }^{17}$; tendencia que se sostiene durante el mes siguiente, teniendo como eje ordenador la actividad desarrollada en conmemoración de la Reforma Universitaria y en repudio a la visita al país del enviado del presidente norteamericano, Nelson Rockefeller, programada para el día 29 de junio. El segundo pico de conflictividad, aunque de menor magnitud que el anterior, se da durante el mes de septiembre del mismo año, con un total de 44 conflictos mensuales, que giraron fundamentalmente en torno a la campaña de homenaje al estudiante Santiago Pampillón ${ }^{18}$ y a las acciones en solidaridad con el conflicto que mantuvieron los obreros ferroviarios durante dicho mes. El siguiente pico tiene lugar nuevamente durante el mes de mayo, pero de 1970, momento en el que se producen 50 conflictos mensuales, ${ }^{19}$ en el marco del primer aniversario del “Cordobazo” y de la muerte de los estudiantes Bello, Cabral y Blanco. ${ }^{20}$ Por último, el cuarto pico de conflictividad es en junio de 1971, siendo no solo el de mayor magnitud para el movimiento estudiantil (54), sino que además coincide con el momento de mayor conflictividad obrera en la región ${ }^{21}$ y de una activación general de la protesta social en el interior del país. A mediados de 1971 la región no solo estaría en presencia de la etapa de mayor combatividad del movimiento estudiantil, sino también en uno de los momentos en donde los lazos con la clase obrera alcanzan mayor profundidad, en el marco de una de las grandes huelgas en aquella etapa: la de los obreros textiles de Petroquímica Sudamericana. A pesar de la aparente dispersión, originada en las divergencias entre las distintas tendencias estudiantiles, el combate callejero y la necesidad de estrechar los vínculos con las luchas de los trabajadores textiles marcaron la tónica general de las luchas que se desplegaron a mediados de 1971.

Independientemente de lo que estamos señalando, podríamos mencionar otra particularidad de la dinámica de la conflictividad del movimiento estudiantil que estaría vinculada con el hecho de que pareciera haber cierta correspondencia entre el incremento de la actividad represiva y una mayor intensidad de la protesta estudiantil. 
TABLA I

Frecuencia y promedio diario de los conflictos estudiantiles 1969-1972. Gran La Plata

\begin{tabular}{llll}
\hline Presidencias & Frecuencia & Porcentaje & $\begin{array}{l}\text { Promedio } \\
\text { diario }\end{array}$ \\
\hline Onganía & 387 & 36,8 & 0,73 \\
Levingston & 193 & 18,4 & 0,67 \\
Lanusse & 470 & 44,8 & 0,72 \\
$\quad$ Sub Lanusse a (23/03/71- & 244 & & 1,09 \\
31/10/71) & & 0,53 \\
$\quad$ Sub Lanusse b $(01 / 11 / 71-$ & 226 & &
\end{tabular}

Fuente: elaboración propia en base a información periodística extraída del diario "El Día".

TABLA II

Masividad de los conflictos estudiantiles 1969-1972. Gran La Plata

\begin{tabular}{lllll}
\hline Presidencias & $\begin{array}{l}\text { Hasta } 50 \\
\text { personas }\end{array}$ & $\begin{array}{l}\text { De } 50 \text { a } 500 \\
\text { personas }\end{array}$ & $\begin{array}{l}\text { Más de } 500 \\
\text { personas }\end{array}$ & Total \\
\hline Onganía & $63,6 \%$ & $27,9 \%$ & $8,5 \%$ & $100 \%(387)$ \\
Levingston & $53,4 \%$ & $37,3 \%$ & $9,3 \%$ & $100 \%(193)$ \\
Lanusse & $37,6 \%$ & $51,5 \%$ & $10,9 \%$ & $100 \%(470)$ \\
$\quad$ Sub Lanusse a $(23 / 03 / 71-31 / 10 / 71)$ & $40,9 \%$ & $47,7 \%$ & $11,4 \%$ & $100 \%(244)$ \\
$\quad$ Sub Lanusse b $(01 / 11 / 71-31 / 12 / 72)$ & $34 \%$ & $55,9 \%$ & $10,1 \%$ & $100 \%(226)$ \\
\hline Total & $50,1 \%$ & $40,2 \%$ & $9,7 \%$ & $100 \%(1050)$ \\
\hline
\end{tabular}

Fuente: elaboración propia en base a información periodística extraída del diario "El Día".

Si modificamos el criterio de periodización (de uno meramente cronológico a otro cuyo eje serían los distintos momentos institucionales bajo el gobierno de la "Revolución Argentina", es decir la sucesión de las tres presidencias de Onganía, Levingston y Lanusse), se puede observar (véase tabla I) que durante la presidencia de Levingston el promedio diario de conflictos $(0,67)$ es el más bajo de los tres periodos, encontrándose por ende por debajo de la media. Durante dicha presidencia el contexto político más general estuvo signado por contradicciones crecientes en el seno de la Fuerzas Armadas, y entre éstas y los sectores empresariales y políticos, lo que en algún punto resintió la capacidad represiva del gobierno, a pesar de que el mismo denotara una actitud más reticente a establecer canales de negociación y diálogo.

Por el contario, el promedio diario de conflictos asciende a valores prácticamente similares para el caso de las presidencias de Onganía y Lanusse ( 0,73 y 0,72 respectivamente), gobiernos que potenciaron los aparatos represivos en la estructura del Estado, ampliando sus capacidades operativas y perfeccionando nuevas prácticas y actividades de control social y político, aspectos que evidentemente repercutieron también en las modalidades y dinámicas propias que presentó la protesta social. Desde nuestro punto de vista, la intervención represiva del gobierno determinará, muchas veces, la intensificación (y radicalización) de la conflictividad estudiantil, que por añadidura se convierte en un punto focal de la oposición de amplios sectores de la sociedad civil al autoritarismo del gobierno. De todos modos deberíamos introducir una aclaración con respecto al gobierno de Lanusse. Durante su presidencia se vuelve más manifiesta la dualidad de la táctica desplegada por la dictadura militar con posterioridad al Cordobazo, es decir una táctica de tregua y apertura hacia la fracción "moderada" del movimiento de protesta social por un lado, y del otro la represión hacía el sector más dinámico de ese movimiento. Esta dualidad influirá, en nuestra opinión, en el derrotero de la conflictividad hacia el final de nuestro periodo. Por ejemplo, si subdividimos la presidencia de Lanusse en 
dos subperiodos, (del 23/03/71 al 31/10/71 el primero y del 01/11/71 al 31/12/72 el segundo), el promedio diario de conflictos asciende a 1,09 en el primero de ellos, lo que representaría uno de los momentos de mayor intensidad de la conflictividad estudiantil durante todo periodo 1969-1972. Sin embargo, una vez que la "apertura democrática" se encontró en una etapa bastante avanzada, convirtiéndose la "retirada" del régimen militar en un hecho incuestionable, la conflictividad estudiantil finalmente acusó una importante reducción. En el segundo subperiodo el promedio diario desciende $(0,53)$ hasta ubicarse por debajo de la media, obteniendo valores similares a los del periodo de Levingston.

Estas tendencias del ciclo de protesta del movimiento estudiantil que estamos presentando las podríamos complejizar si nos enfocamos en la masividad que evidenciaron estos conflictos. En primer lugar, destacando una característica de la conflictividad estudiantil, que la profundizaremos más adelante, y que se vuelve más notoria cuando la cotejamos con las tendencias registradas para el caso del movimiento obrero. Si bien las acciones que protagonizan las estudiantes son la mitad de las que motoriza el movimiento obrero, aquellas involucraron no obstante a una mayor cantidad de sujetos. Los conflictos del movimiento estudiantil resultaron más masivos si los comparamos con los desarrollados por el movimiento obrero. Como se desprende de la tabla II, si tomamos toda la etapa 1969-1972 la mitad de las acciones protagonizadas por el movimiento estudiantil involucran a un pequeño grupo de personas (es decir de menos de 50 personas), mientras que en las que se encuentran involucrados de 50 a 500 personas y de más de 500 los porcentajes son del orden del 40,2\% y del 9,7\% respectivamente. De manera que mientras el 50\% de los conflictos llevados a cabo por el movimiento estudiantil involucran a por lo menos más de 50 sujetos, el porcentaje para el caso del movimiento obrero solo representa el 30,2\%. Por añadidura, la masividad de las acciones tendió a aumentar a medida que nos acercamos hacia el final del periodo seleccionado, a pesar de que la frecuencia de las acciones, como ya vimos, sufría al mismo tiempo una disminución. En la tabla II se puede advertir que si durante la presidencia de Onganía solo en el 36,4\% de las acciones participan más de 50 personas, ya en la presidencia de Lanusse un poco más del $60 \%$ de las acciones las protagonizan grupos que involucran a más de 50 personas; siendo además levemente más elevado el porcentaje (10,9\%) de acciones en las que actúan grupos compuestos por más de 500 personas. Por añadidura, si subdividimos el periodo de Lanusse se puede también observar cierto contraste. Al desagregar la presidencia de Lanusse en dos subperiodos hallábamos una disminución del promedio de conflictos diarios hacía el segundo de dichos subperiodos, sin embargo no sucede lo mismo con la masividad de las acciones, que alcanzan los mayores valores de todo el periodo 1969-1972 (el 55,9\% para la variable de "de 50 a 500" y de 10,1\% para la variable "de 500 a miles"). Lo que estos datos nos estarían indicando es que si bien la apertura política emprendida por el gobierno de Lanusse, y sus repercusiones en el plano universitario, logra disminuir en términos cuantitativos la conflictividad de un sector del movimiento estudiantil, no logra concretar el mismo efecto en la masividad de la protesta de los sectores que se mantuvieron activos, que por el contrario se intensifica.

\section{CICLO DE PROTESTA, FORMAS ORgANIZACIONALES Y CORRIENTES POLÍTICO-IDEOLÓGICAS}

Otro de los aspectos que se desatacan de este ciclo de conflictividad estudiantil que estamos analizando es que el mismo estuvo protagonizado en gran medida por lo que podríamos considerar como actores tradicionales o clásicos del movimiento estudiantil argentino, ya sea tanto desde el punto de vista de las propias instancias organizativas como desde la adscripción política-ideológica de las mismas. Para establecer una primera aproximación a esta problemática hemos establecido una distinción entre, por un lado, las acciones cuya iniciativa le corresponde exclusivamente a las agrupaciones o tendencias políticas y las federaciones, y las que, por el otro, son protagonizadas por los distintos centros de estudiantes (u otras instancias de representación estudiantil) que actuaban en las distintas facultades que componían la UNLP. ${ }^{22}$ En primer término, se destaca el casi similar protagonismo que presentan las dos, en tanto que de las 987[23] acciones que inician los sujetos estudiantiles, el 61,3\% (605) corresponden a centros de estudiantes, mientras que en el 38,7\% 
(381) restante son exclusivamente protagonizadas por las distintas tendencias, agrupaciones y federaciones. [24] Entre estas últimas quién adquiere una clara preeminencia es la FULP, desarrollando por sí sola el 40,2\% de las acciones (véase tabla III).

TABLA III

Filiación política-organizacional estudiantil. Gran La Plata. 1969-1972.

\begin{tabular}{llllll}
\hline $\begin{array}{l}\text { Tendencias o } \\
\text { Federaciones }\end{array}$ & 1969 & 1970 & 1971 & 1972 & Total \\
\hline FULP & $34,2 \%$ & $45,2 \%$ & $41,0 \%$ & $37,1 \%$ & $40,2 \%$ \\
FUA & $0,9 \%$ & $2,7 \%$ & $3,6 \%$ & $2,9 \%$ & $2,4 \%$ \\
FUA-LP (MOR) & $0 \%$ & $0,7 \%$ & $1,2 \%$ & $0 \%$ & $0,5 \%$ \\
Franja Morada & $18,8 \%$ & $17,8 \%$ & $7,2 \%$ & $5,7 \%$ & $14,7 \%$ \\
FURN & $12,8 \%$ & $11,6 \%$ & $13,3 \%$ & $17,1 \%$ & $12,9 \%$ \\
FAEP & $0 \%$ & $0 \%$ & $1,2 \%$ & $0 \%$ & $0,3 \%$ \\
CNU & $0,9 \%$ & $1,4 \%$ & $1,2 \%$ & $2,9 \%$ & $1,3 \%$ \\
TAR & $5,2 \%$ & $0 \%$ & $7,2 \%$ & $0 \%$ & $3,2 \%$ \\
FAUDI & $0 \%$ & $2,1 \%$ & $4,8 \%$ & $2,9 \%$ & $2,1 \%$ \\
TAREA & $6,0 \%$ & $0,0 \%$ & $0,0 \%$ & $0,0 \%$ & $1,8 \%$ \\
MOR & $3,4 \%$ & $3,7 \%$ & $7,2 \%$ & $5,7 \%$ & $4,2 \%$ \\
MAP (Ing.) & $2,6 \%$ & $1,4 \%$ & 0 & 0 & $1,3 \%$ \\
FULP y FURN & $2,6 \%$ & $4,8 \%$ & $7,2 \%$ & $8,6 \%$ & $5,0 \%$ \\
Otros & $10,3 \%$ & $8,2 \%$ & $4,8 \%$ & $16,2 \%$ & $8,3 \%$ \\
\hline Total & $100 \%(116)$ & $100 \%(146)$ & $100 \%(83)$ & $100 \%(36)$ & $100 \%$ \\
& & & & & $(381)$ \\
\hline
\end{tabular}

Fuente: elaboración propia en base a información periodística extraída del diario "El Día".

*Véase nota 24.

Por añadidura, la FULP adquiere mayor centralidad en los momentos en donde la protesta se intensificaba en términos cuantitativos, es decir durante los años 1970 y 1971. Lo cual, por otro lado, nos habla de la predominancia en el caso platense ya no solo de las instancias clásicas de representación estudiantil, ${ }^{25}$ sino también de la persistencia del acervo ideológico tradicional del movimiento estudiantil: el reformismo. ${ }^{26}$

La Federación era conducida desde 1969 por la Tendencia Reformista Franja Morada (FM), y en minoría por el FAUDI (Federación de Agrupaciones Universitarias de Izquierda). ${ }^{27}$ Por añadidura, esta preeminencia de FM en la FULP se refuerza por la circunstancia de ser la segunda agrupación en orden de importancia con el 14,7\% de las acciones, aunque con una tendencia decreciente a lo largo de toda la etapa, ya que pasa de protagonizar el $18,8 \%$ de los conflictos en 1969 al $5,7 \%$ en $1972 .{ }^{28}$

Este aspecto que estamos señalando se torna más evidente si tenemos en cuenta que la intervención a las universidades en 1966 y la aplicación de un nuevo régimen de enseñanza universitario había tenido como consecuencia cierta dispersión dentro del estudiantado, lo que determinó que varios centros de estudiantes, y hasta la propia FULP, no pudieran renovar sus autoridades. Cabe destacar, como ya señalamos, que en el caso de la UNLP la "intervención" aplica su política con ciertos matices, ya que, a diferencia de otras universidades, no se disuelven Centros ni la Federación y se permite el desenvolvimiento de algunas Cooperativas estudiantiles, lo que le otorga al movimiento estudiantil platense algún marco de legalidad posibilitándole cierto accionar independiente.

La hegemonía del reformismo y de la FULP intentaba ser cuestionado por la FURN (Federación Universitaria de la Revolución Nacional), tendencia que reivindicaba la tradición nacionalista y se proponía como meta introducir el peronismo en las universidades. ${ }^{29}$ De todos modos, bajo nuestro periodo, no logró disputarle la hegemonía al reformismo por lo menos en plano de la conflictividad. Como se puede observar en la tabla III, la FURN solo mantuvo la iniciativa por sí misma en el 12,9\% de las acciones, aunque alcanzó 
proporcionalmente un mayor protagonismo hacia el año 1972 (17,1\%). Este débil protagonismo de la corriente peronista mayoritaria ${ }^{30}$ en el ámbito estudiantil platense se torna más patente si tenemos en cuenta su autoexclusión de la actividad de los centros estudiantiles. Sin embargo, deberíamos introducir un matiz, ya que a pesar de su animadversión a las corrientes reformistas en la Universidad, es interesante observar en la tabla III que no obstante las acciones realizadas en conjunto con la FULP tuvieron cierta importancia, en tanto que en momentos particularmente intensos de la conflictividad, como el año 1971, alcanzaron el $7,2 \%$ de las acciones realizadas. De todos modos, en nuestra opinión estos datos, además, nos obligarían a no circunscribir el proceso de radicalización y politización del estudiantado (que analizaremos específicamente en el próximo apartado) al proceso de "peronización", tal como sugieren algunas interpretaciones (Barletta, 2001).

Esta predominancia del reformismo en el mapa político del movimiento estudiantil platense se corrobora si nos enfocamos en la actividad de los centros de estudiantes. De la actividad de los mismos se desprende que algunos centros presentaron una mayor militancia que otros. En términos generales, es decir tomando todo el periodo 1969-1972, los cinco centros que tuvieron cierta centralidad en la conflictividad estudiantil (ya que explican casi la mitad de las acciones, véase tabla IV), son en primer lugar el Centro de Estudiantes de Derecho (13,2\% de las acciones), seguido por el de Ciencias Veterinarias (10,6\%), Humanidades (8,8\%), Ciencias Médicas (8,6\%) y Ciencias Económicas (7,3\%). Con la excepción de Ciencias Veterinarias, todos ellos fueron conducidos, bajo nuestro periodo, por agrupaciones que, aunque con variantes, se reconocían en la tradición reformista: FM, FAUDI y MOR (Movimiento de Orientación Reformista).31

Como decíamos la excepción en este cuadro la representa el caso del Centro de Estudiantes de Ciencias Veterinarias, presentando cierta particularidad dentro del panorama político estudiantil platense, ya que la conducción del centro de estudiantes no respondía a ninguna de las tendencias mayoritarias. En verdad, era una de las pocas facultades de la UNLP en la que los sectores social-cristianos, a través de la lista Ateneo de Veterinarias, lograron ser conducción del Centro de Estudiantes durante los primeros años de la intervención, ${ }^{32}$ con una agrupación que definía su acción como de carácter exclusivamente gremialista y apolítico. Efectivamente, dicho centro de estudiantes mantuvo un sostenido proceso de lucha en contra de las autoridades universitarias motorizada fundamentalmente por reclamos corporativos, tales como por la derogación de los cursos de ingresos, separación de docentes, derogación del sistema de materias básicas, nuevos llamados a exámenes, etc; y que derivó en varias ocasiones en la toma tanto de la facultad como del edificio del rectorado. Lo cual daría cuenta de que no en todos los casos habría una relación unilineal entre mayor intensidad de la militancia y politización, aspectos que profundizaremos en el apartado siguiente. En algunos sectores las demandas de índole propiamente corporativa podían dar lugar a procesos sostenidos de luchas. En espejo podríamos citar el caso del CEILP (Centro de Estudiantes de Ingeniería La Plata). Históricamente dicho centro ocupaba un lugar muy destacado en el mapa político de la UNLP, presentado asimismo un peso específico muy importante en el seno de la FULP. No obstante ello, durante nuestro periodo dicha centralidad no se vio reflejada en el mapa de la conflictividad estudiantil, en la medida en que solo el $6,1 \%$ del total de las acciones corresponde a iniciativas provenientes exclusivamente de dicho centro. ${ }^{33}$ 
TABLA IV

Centros de estudiantes. Gran La Plata. 1969-1972.

\begin{tabular}{|c|c|c|c|c|c|}
\hline Centros de Estudiantes & 1969 & 1970 & 1971 & 1972 & Total \\
\hline Centros de Estudiantes de la UTN & $0 \%$ & $0,8 \%$ & $0,5 \%$ & $0,7 \%$ & $0,5 \%$ \\
\hline $\begin{array}{l}\text { Centros de Estudiantes de Escuelas } \\
\text { Técnicas }\end{array}$ & $0 \%$ & $0 \%$ & $0 \%$ & $10,2 \%$ & $2,5 \%$ \\
\hline $\begin{array}{l}\text { Centros de Estudiantes de Escuelas } \\
\text { Secundarias }\end{array}$ & $0,9 \%$ & $0,8 \%$ & $2,8 \%$ & $4,8 \%$ & $2,5 \%$ \\
\hline $\begin{array}{l}\text { Centro de Estudiantes de } \\
\text { Humanidades }\end{array}$ & $20,5 \%$ & $10,2 \%$ & $6,9 \%$ & $1,4 \%$ & $8,8 \%$ \\
\hline $\begin{array}{l}\text { Centro de Estudiantes de Ciencias } \\
\text { Médicas }\end{array}$ & $7,1 \%$ & $10,9 \%$ & $8,7 \%$ & $7,5 \%$ & $8,6 \%$ \\
\hline Centro de Estudiantes de Derecho & $18,8 \%$ & $18,0 \%$ & $13,8 \%$ & $4,1 \%$ & $13,2 \%$ \\
\hline $\begin{array}{l}\text { Centro de Estudiantes de Ciencias } \\
\text { Exactas }\end{array}$ & $6,3 \%$ & $5,5 \%$ & $7,8 \%$ & $2,7 \%$ & $5,8 \%$ \\
\hline Centro de Estudiantes de Ingeniería & $6,3 \%$ & $9,4 \%$ & $6 \%$ & $3,4 \%$ & $6,1 \%$ \\
\hline $\begin{array}{l}\text { Centro de Estudiantes de } \\
\text { Veterinarias }\end{array}$ & $1,8 \%$ & $2,3 \%$ & $13,3 \%$ & $20,4 \%$ & $10,6 \%$ \\
\hline $\begin{array}{l}\text { Centro de Estudiantes de } \\
\text { Agronomía }\end{array}$ & $2,7 \%$ & $7 \%$ & $6,9 \%$ & $6,8 \%$ & $6,1 \%$ \\
\hline $\begin{array}{l}\text { Centro de Estudiantes de } \\
\text { Periodismo }\end{array}$ & $0 \%$ & $0,8 \%$ & $0 \%$ & $0 \%$ & $0,2 \%$ \\
\hline $\begin{array}{l}\text { Centro de Estudiantes de } \\
\text { Odontología }\end{array}$ & $1,8 \%$ & $0 \%$ & $11 \%$ & $14,4 \%$ & $4,5 \%$ \\
\hline $\begin{array}{l}\text { Centro de Estudiantes de Ciencias } \\
\text { Económicas }\end{array}$ & $16,1 \%$ & $7 \%$ & $6,9 \%$ & $1,4 \%$ & $7,3 \%$ \\
\hline $\begin{array}{l}\text { Centro de Estudiantes de } \\
\text { Arquitectura. }\end{array}$ & $2,7 \%$ & $8,6 \%$ & $5 \%$ & $4,8 \%$ & $5,3 \%$ \\
\hline $\begin{array}{l}\text { Centro de Estudiantes de Ciencias } \\
\text { Naturales }\end{array}$ & $5,4 \%$ & $13,3 \%$ & $3,7 \%$ & $0,7 \%$ & $5,3 \%$ \\
\hline $\begin{array}{l}\text { Centro de Estudiantes de Bellas } \\
\text { Artes }\end{array}$ & $1,8 \%$ & $0 \%$ & $5 \%$ & $0,7 \%$ & $2,3 \%$ \\
\hline $\begin{array}{l}\text { Combinación de Centros de Centros } \\
\text { de Estudiantes y lo otras } \\
\text { organizaciones, etc }\end{array}$ & $8 \%$ & $5,5 \%$ & $11 \%$ & $16,3 \%$ & $10,6 \%$ \\
\hline Total & $\begin{array}{l}100 \% \\
(112)\end{array}$ & $\begin{array}{l}100 \% \\
(128)\end{array}$ & $\begin{array}{l}100 \% \\
(218)\end{array}$ & $\begin{array}{l}100 \% \\
(147)\end{array}$ & $\begin{array}{l}100 \% \\
(605)^{*}\end{array}$ \\
\hline
\end{tabular}

Fuente: elaboración propia en base a información periodística extraída del diario "El Día".

* Véase nota 24

\section{CONFLICTIVIDAD ESTUDIANTIL Y RADICALIZACIÓN POLÍTICA}

Si profundizamos el análisis tanto en los objetivos explícitos y específicos por los cuales se inician las distintas acciones, como en las formas y características concretas que adquirió la conflictividad, podríamos contemplar otra de las particularidades que presenta el movimiento estudiantil platense. Como veremos a continuación, en términos generales el ciclo de conflictividad estudiantil se terminó expresando en formas de luchas que dieron cuenta de importantes niveles de combatividad y de radicalización política, fundamentalmente si lo comparamos con el caso del movimiento obrero regional.

$\mathrm{Si}$ analizamos las demandas que articularon los conflictos del movimiento estudiantil, nos encontramos con que gran parte de las luchas estuvieron motorizadas por reclamos de orden extra-corporativo (véase figura IV). ${ }^{34}$ A diferencia de lo que encontramos en el caso del movimiento obrero, el 61,4\% de los conflictos estudiantiles durante la etapa 1969-1972 se refieren exclusivamente a luchas de carácter político, seguidas en orden de importancia por las luchas de orden corporativo $(32,4 \%)$ y en última instancia y con valores marginales, por los conflictos al interior del propio movimiento estudiantil, es decir entre las distintas tendencias, agrupaciones, centros de estudiantes, etc (5,8\%). ${ }^{35}$ Dichos datos, nos estarían indicando en 
una primera instancia, el mayor nivel de politización que presentaba en términos generales el movimiento estudiantil, por lo menos en comparación con las tendencias observadas para el movimiento obrero regional. Ésta mayor politización se volvía más aguda, además, en los momentos en los que en el plano nacional recrudecía la política de represión, en tanto que los reclamos corporativos (tales como las luchas por el ingreso irrestricto) perdían momentáneamente cierta centralidad.

El vínculo entre una mayor intensidad de la política represiva y una mayor politización se puede corroborar si observamos las demandas concretas al interior de los conflictos de carácter extra-corporativos, en donde adquieren gran centralidad las luchas ordenadas alrededor de la oposición y rechazo a la política represiva del régimen militar y de otras organizaciones de "derecha", ya que el 40,2\% de las acciones cuyos fines se ubican en el orden político se refieren a reclamos específicamente en contra de "la represión armada estatal", por la solicitud de "libertad de detenidos o de presos políticos" y en repudio a "atentados específicos, amenazas de muerte, etc". Dentro de este ámbito de lucha le siguen, en orden de importancia con el 20,3\% de las acciones, las manifestaciones de solidaridad, apoyo o adhesión a procesos de lucha fundamentalmente del movimiento obrero, y también de otros sectores del movimiento estudiantil, lo que daría cuenta del lugar estratégico que ocupaba la alianza obrero-estudiantil para un sector importante del movimiento estudiantil platense, tal como sostuvimos al comienzo.

Pero, además, de manera paralela las luchas del movimiento estudiantil giraron en torno a lo que se consideraba como una "ofensiva limitacionista". En lo que respecta a las luchas de carácter corporativo, los conflictos en contra del sistema de ingreso, $y / u$ otras medidas limitacionistas ${ }^{36}$, resultan ser un eje alrededor del cual se ordena gran parte de la conflictividad del movimiento estudiantil, ya que representan el 41,9\% de las acciones cuyos fines se corresponden a demandas corporativas. Seguidas por las demandas de reformas al plan de estudios, en rechazo al bajo nivel de algunas cátedras y por el matiz ideológico que se le imprimen a determinadas materias $(17,2 \%)$, solicitando el alejamiento o renuncia de docentes o autoridades $(11,3 \%)$ y por el aumento general del presupuesto universitario $(7,2 \%)$.

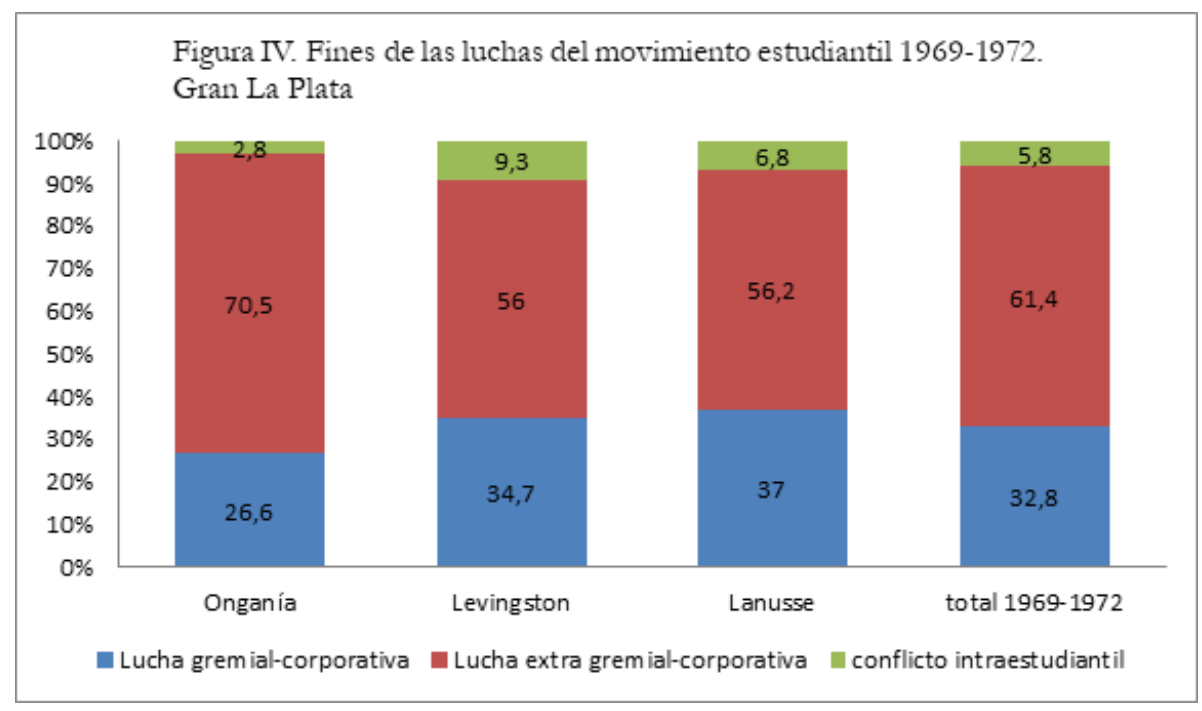

Fuente: elaboración propia en base a información periodística extraída del diario "El Día”

Si bien estamos sosteniendo que, en términos generales, las luchas de orden político son las predominantes frente a las de orden corporativo, no obstante estas últimas comienzan a cobrar mayor importancia hacia el final del periodo. Como se puede observar en la figura IV, del primer al último periodo los conflictos de orden extra-corporativos, sin dejar de ser mayoritarios, disminuyen sensiblemente, ya que pasan de representar el 70,5\% en el periodo de Onganía al 56,0\% y 56,2 en los dos periodos subsiguientes. ${ }^{37}$ Más aún, si nos desplazamos al criterio de periodización cronológico, dicha tendencia se vuelve aún más pronunciada. En la figura $\mathrm{V}$ se puede divisar una tendencia progresiva de disminución de las luchas políticas, que de encontrarse 
en el primer lugar con el 73,4\% de las acciones durante el año 1969 descienden al 46\% en 1972, cediendo el primer lugar a las luchas gremiales, que se duplican desde el primer año al último, llegando a representar el $50,5 \%$ de las acciones. Si relacionamos esta tendencia con lo desarrollado previamente respecto a la intensidad y masividad de la conflictividad estudiantil, podríamos conjeturar que no habría necesariamente una relación lineal entre intensificación y masificación de las luchas del movimiento estudiantil y una mayor radicalidad y politización de las demandas. Por el contrario, lo que puede observarse en nuestro caso es que a medida que los procesos de lucha adquieren mayor intensidad, los reclamos corporativos alcanzan proporcionalmente mayor importancia. No resultaría ajeno a esta tendencia, la circunstancia de que el resurgimiento de la actividad de los partidos políticos hacia el final de la etapa, permite que éstos logren articular nuevamente diversas demandas, que las distintas organizaciones corporativas se habían visto obligadas a asumir en el marco de un Estado autoritario. Esta dinámica se verá reflejada en el mapa político de los centros de estudiantes. En un estudio previo (Nava, 2013) pudimos apreciar como durante 1972 parece haber un retroceso de las tendencias de izquierda, en particular del FAUDI. Proceso que tiene como contrapartida la inclinación creciente del estudiantado hacia las agrupaciones cuyos énfasis estaban enfocados en la necesidad de desarrollar organismos representativos y consolidados, que hicieran hincapié en los problemas concretos de los estudiantes.

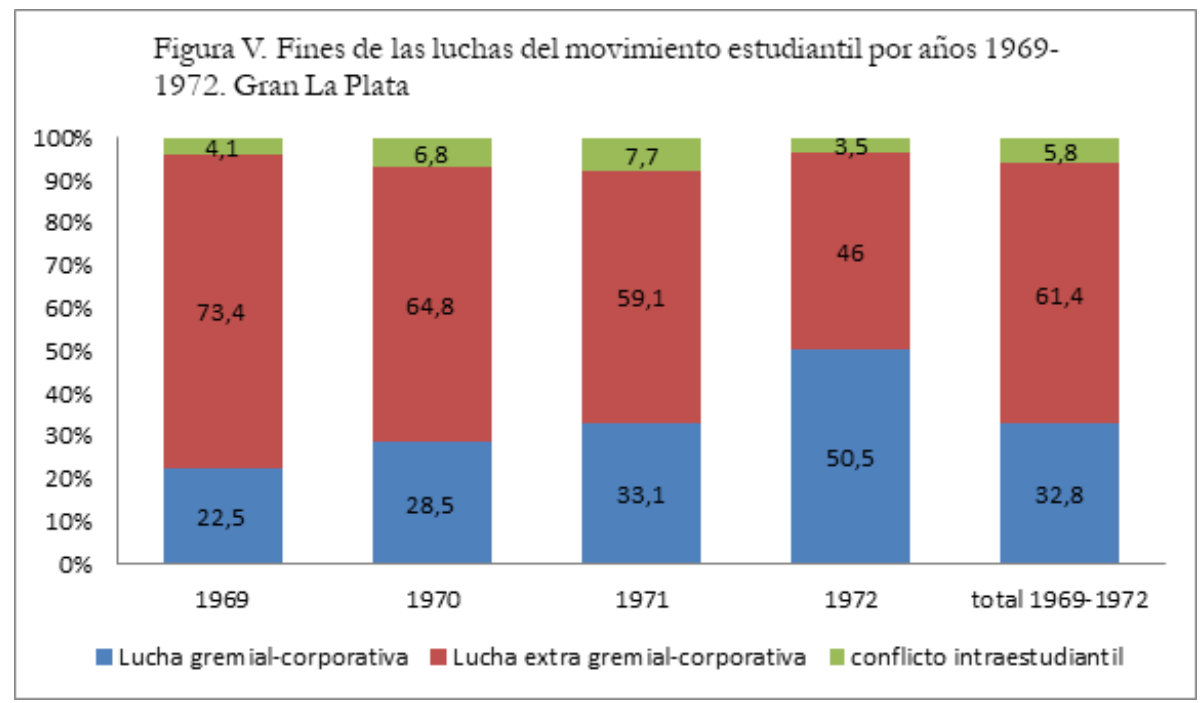

Fuente: elaboración propia en base a información periodística extraída del diario "El Día”.

No obstante esta tendencia a largo plazo, en general las luchas del movimiento estudiantil se desplazaron al plano político con mayor facilidad que en el caso del movimiento obrero local. No solo eso, sino que también, en consonancia con lo que veníamos sosteniendo, tuvieron una mayor propensión a ubicar como eje de confrontación a la dictadura militar y su proyecto político-económico más amplio. Si bien este aspecto ameritaría un análisis en mayor profundidad, todavía en el marco del análisis cuantitativo, hemos utilizado otro modo de agrupar los fines que se expresan en las luchas para poder dar cuenta de los alineamientos expresados por los distintos sectores del movimiento estudiantil en relación a las alternativas presentes en el ciclo de protesta más general que se desarrollaba en el plano nacional, y su posicionamiento más concreto con respecto al régimen militar, por medio de tres variables: rechazo formal/en disputa, a favor del régimen militar y contra el régimen militar. ${ }^{38}$

Como se puede observar en la figura VI, en este caso surgirían dos aspectos a destacar. En primer lugar, en lo que respecta al movimiento estudiantil hay un leve predominio en términos generales de los alineamientos que se concentran bajo la categoría "contra el régimen militar", con un 53,8\% del total de las acciones realizadas bajo el periodo 1969-1972. Dicha tendencia cobra mayor relevancia si tenemos en cuenta que en el caso del movimiento obrero solo un $23,9 \%$ de los conflictos se dirige expresamente en contra del 
régimen militar. Sin embargo, si nos detenemos en la dinámica a lo largo del periodo, se puede apreciar como el predominio de este tipo de conflicto se atenúa a medida que nos acercamos al final del periodo, para finalmente ceder el lugar en 1972 a las luchas agrupadas bajo la categoría rechazo formal/en disputa que llegan a presentar el 59,4\% de las acciones. Es decir acciones en donde se rechazan aspectos parciales ya sea de la política llevada adelante por el gobierno militar, o de las autoridades universitarias, aunque sin llegar a proponer una alternativa política diferente a la puesta en práctica por el gobierno. Dichos datos nuevamente nos obligan a no relacionar de manera directa los procesos de intensificación- masificación de la protesta social y la politización y radicalización de las luchas. Por el contrario, nos veríamos tentados a sostener que en muchas ocasiones fueron los reclamos corporativos los que terminan motorizando los conflictos del movimiento estudiantil, aunque en una proporción menor que la encontrada en el caso del movimiento obrero.

En nuestra opinión, estas tendencias nos permitirían conjeturar y sostener que si bien la estrategia política del GAN (Gran Acuerdo Nacional) no logra impedir que las luchas adquieran una mayor masividad, tienen particularmente mayor éxito a la hora de evitar que la misma se politizara aún más. En tanto que a medida que nos acercamos a la salida electoral las luchas en donde los objetivos explícitos se encontraban acotados a los intereses específicos de los estudiantes crecieron aún más en intensidad con respecto a las luchas contra el régimen militar. Tendencia que en sí misma, por añadidura, contribuía a que los conflictos estudiantiles se aislaran de algún modo de los conflictos que mantenían el movimiento obrero y otros sujetos altamente movilizados del periodo, lo cual en sí mismo era uno de los objetivos que se proponía el régimen militar.

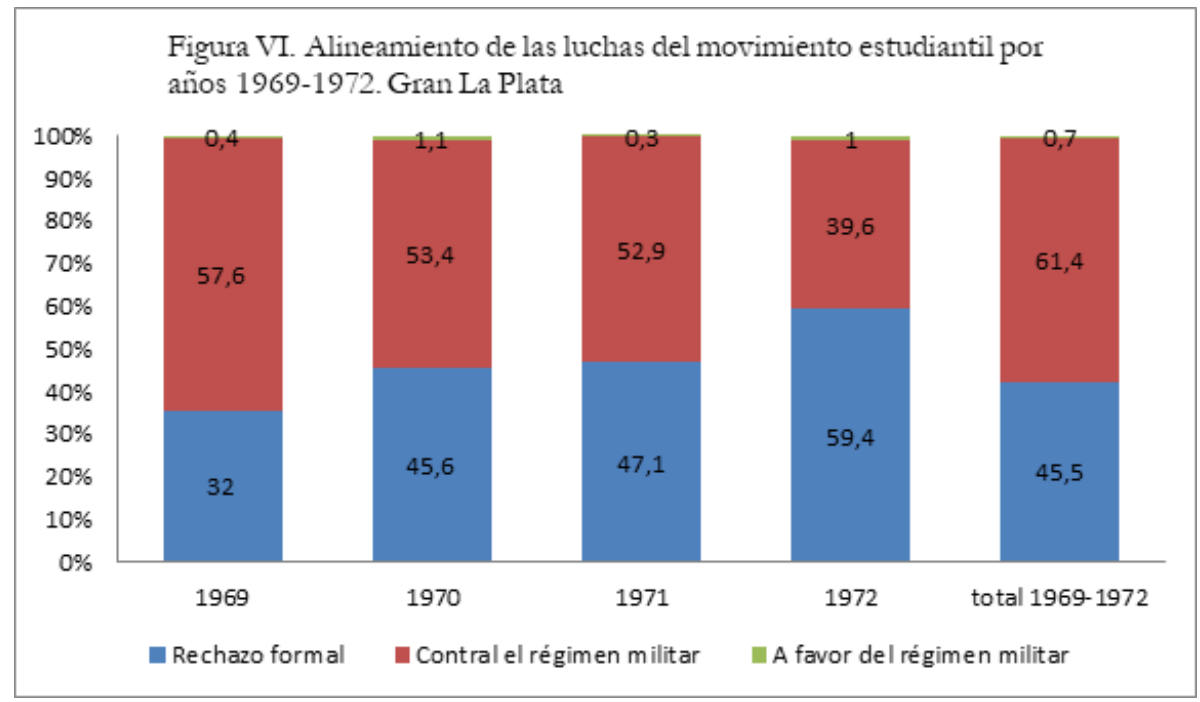

Fuente: elaboración propia en base a información periodística extraída del diario "El Día".

Independientemente de estas tendencias, otra de las particularidades por las cuales se destacó el movimiento estudiantil fue por el alto grado de radicalidad que le imprimieron a sus acciones. Tengamos en cuenta que la tónica que adquiere el ciclo de conflictividad estudiantil quedaría incompleta si solo nos enfocamos en cuáles fueron sus demandas explícitas. Para acceder a una comprensión más cabal de dicho proceso deberíamos analizar asimismo las formas y características concretan que tuvieron las acciones impulsadas por el movimiento estudiantil, que fue otro de los modos por el cual hemos intentando acceder a los niveles de radicalización. En este sentido, para abordar el grado de violencia material presente en los enfrentamientos hemos establecido en primer lugar una distinción entre los enfrentamientos verbales/ escritos (es decir la forma más suave del conflicto en tanto que el medio utilizado es la palabra ${ }^{39}$ ) y los de carácter material.

En el caso del movimiento estudiantil, bajo el periodo 1969-1972, encontramos que en promedio las acciones de tipo material superan ampliamente a las de carácter verbal/escrito (60\% a 40\%), una proporción 
similar a la que encontramos en el caso del movimiento obrero. En la tabla $\mathrm{V}$ se puede observar la desagregación de estas dos variables. En lo que respecta a toda la etapa 1969-1972, las declaraciones, los pronunciamientos, las convocatorias y los reclamos, representan el 37,8\% de los hechos realizados por el movimiento estudiantil platense. Con lo cual se convierten en el tipo de hecho de mayor recurrencia. Aunque, como también se desprende de la tabla $\mathrm{V}$, acusan una tendencia decreciente bastante marcada a lo largo de los distintos periodos. En segundo orden de importancia se ubicarían las instancias más propiamente deliberativas, tales como las reuniones, las asambleas, etc, con el 22,1\% de las acciones. Lo que representa un valor cuatro veces superior a los hechos en donde prevalece el ámbito más negociador (entrevistas, reuniones, negociaciones entre partes, etc.), tanto con las autoridades universitarias como con otros sujetos, que solo significan el 6,4\%. De todos modos, este tipo de acciones parecen volverse más comunes a medida que la salida democrática se hace más concreta.

Sin embargo, como decíamos, lo que caracterizó al movimiento estudiantil fue la mayor propensión a desarrollar las modalidades de luchas más disruptivas. Es decir, las consideradas clásicamente como medidas de fuerza (paros o las ocupaciones de los distintos establecimientos universitarios, que implicaban la interrupción de las actividades académicas), que representaron un 12,5\%, o los actos, concentraciones, movilizaciones, etc. que representaron el 15,6\% del total de las acciones realizadas bajo la etapa 1969-1972. 40 Claramente las "calles" representaron un ámbito predilecto de la acción del movimiento estudiantil. Por añadidura ambos tipos de hechos presentan una leve tendencia ascendente a lo largo de los sucesivos periodos. En verdad la dinámica de los actos, concentraciones, marchas, etc. si bien es creciente, adquiere la fisonomía de una U; ya que su nivel más bajo $(8,8 \%)$ tiene lugar durante la presidencia de Levingston, para ascender a su nivel más elevado en el periodo de Lanusse $(22,1 \%)$, adquiriendo una importancia similar a las instancias deliberativas y verbales. A diferencia del movimiento obrero la importancia que adquieren las que estamos considerando como medidas de fuerza propiamente dichas es superior a la que alcanzan las instancias negociadoras, que a pesar de ser progresivamente más recurrente, no obstante ello es un repertorio de lucha menos utilizado por el movimiento estudiantil que la confrontación directa. Esta mayor propensión del movimiento estudiantil hacia la confrontación directa y a la lucha callejera se corrobora si observamos el ámbito social en donde se desarrollan las acciones (tabla VI). El 13,5\% de las acciones de los estudiantes tienen como escenario la vía pública, porcentaje ampliamente superior al que encontramos en el caso del movimiento obrero (2,6\%). Las “calles" representaron un lugar habitual de expresión y movilización del movimiento estudiantil. 
TABLA V

Tipo de hechos. Movimiento estudiantil. Gran La Plata. 1969-1972.

\begin{tabular}{|c|c|c|c|c|}
\hline Tipo de hecho & & & & \\
\hline & Onganía & Levingston & Lanusse & Total \\
\hline $\begin{array}{l}\text {-Declaración, comunicado, solicitada, anuncio, } \\
\text { noticia, informe, nota, documento, } \\
\text { convocatoria, pedido, reclamo, } \\
\text { pronunciamiento, conferencia de prensa. }\end{array}$ & $48,3 \%$ & $41,5 \%$ & $27,7 \%$ & $37,8 \%$ \\
\hline $\begin{array}{l}\text { - Negociaciones entre partes, conversaciones, } \\
\text { actas, gestiones, proyecto o plan de } \\
\text { negociación, entrevistas, elecciones, etc. }\end{array}$ & $5,4 \%$ & $5,2 \%$ & $7,7 \%$ & $6,4 \%$ \\
\hline $\begin{array}{l}\text {-Reunión, plenario, asamblea, congreso, mesa } \\
\text { redonda interclaustro }\end{array}$ & $18,6 \%$ & $22,8 \%$ & $24,7 \%$ & $22,1 \%$ \\
\hline $\begin{array}{l}\text {-Estado de alerta, estado de movilización, } \\
\text { plan de lucha, etc. }\end{array}$ & $5,2 \%$ & $1,6 \%$ & $0 \%$ & $2,2 \%$ \\
\hline $\begin{array}{l}\text {-Paro o huelga total o parcial, con o sin } \\
\text { concurrencia al establecimiento, ocupación de } \\
\text { establecimiento universitario, etc }\end{array}$ & $9 \%$ & $14,4 \%$ & $14,4 \%$ & $12,5 \%$ \\
\hline $\begin{array}{l}\text {-Acto, concentración, movilización fuera del } \\
\text { ámbito universitario, marcha. }\end{array}$ & $12,2 \%$ & $8,8 \%$ & $22,1 \%$ & $15,6 \%$ \\
\hline -Otros & $1,3 \%$ & $5,7 \%$ & $3,4 \%$ & $3,4 \%$ \\
\hline Total & $\begin{array}{l}100 \% \\
(387)\end{array}$ & $100 \%(193)$ & $\begin{array}{l}100 \% \\
(470)\end{array}$ & $\begin{array}{l}100 \% \\
(1050)\end{array}$ \\
\hline
\end{tabular}

Fuente: elaboración propia en base a información periodística extraída del diario "El Día".

Esta tendencia del movimiento estudiantil a establecer modalidades de lucha más disruptivas frente a las instancias más negociadoras se verá reflejada además en el mayor grado de violencia material que presentan las distintas acciones. Para profundizar este aspecto (el grado de violencia material presente en los enfrentamientos) hemos excluido momentáneamente del análisis a las acciones verbales/escritos y desagregamos la variable enfrentamiento material a su vez en tres subvariables:

a) "Enfrentamiento material, con cuerpos. Puede incluir enfrentamiento verbal"

b) "Enfrentamiento material, con cosas que no son armas de fuego. Puede incluir enfrentamiento con cuerpos"

c) "Enfrentamiento material, con armas de fuego. Puede incluir otras cosas que no son armas de fuego".

Como se puede observar en la tabla VII, las formas de lucha en las que no solo se encuentra implicada la movilización de cuerpos, por ausencia o presencia deliberada de los mismos, sino que además se utilizan otro tipo de objetos (que pueden comprender incluso el empleo de armas de fuego ${ }^{41}$ ), adquieren una relativa importancia para el caso del movimiento estudiantil. Sostenemos esto, ya que si tomamos ambos tipos de lucha, las mismas en conjunto representan el 14,6\% del total de las acciones materiales llevadas a cabo por el movimiento estudiantil bajo el periodo 1969-1972. Por añadidura, al interior de ellas, resultan ser más representativas las que implican algún uso de armas de fuego (8,9\%). Tengamos en cuenta que en el caso del movimiento obrero este tipo de acciones solo significaban valores completamente marginales $(1,8 \%)$. Todo lo cual, nos daría cuenta de la propensión que presentaban los enfrentamientos del movimiento estudiantil no solo a expresar un mayor grado de violencia material, sino además a exceder los marcos institucionaleslegales. 
TABLA VI

Ámbito social en el que tienen lugar los hechos. Gran La Plata. 1969-1972

\begin{tabular}{|c|c|c|c|c|}
\hline \multirow[t]{2}{*}{ Lugar } & & & & \multirow[t]{2}{*}{ Total } \\
\hline & Onganía & Levingston & Lanusse & \\
\hline $\begin{array}{l}\text {-En local sindical, } \\
\text { gremial }\end{array}$ & $1,0 \%$ & $0,0 \%$ & $1,5 \%$ & $1,0 \%$ \\
\hline $\begin{array}{l}\text {-En local patronal: } \\
\text { fábrica, empresa, } \\
\text { lugar de trabajo }\end{array}$ & $0,3 \%$ & $1,0 \%$ & $0,9 \%$ & $0,7 \%$ \\
\hline -En la vía pública & $10,6 \%$ & $8,3 \%$ & $18,1 \%$ & $13,5 \%$ \\
\hline $\begin{array}{l}\text {-Dependencia } \\
\text { Administrativa } \\
\text { universitaria }\end{array}$ & $2,1 \%$ & $4,7 \%$ & $6,6 \%$ & $4,6 \%$ \\
\hline $\begin{array}{l}\text {-Facultad y lo } \\
\text { dependencias } \\
\text { estudiantiles. }\end{array}$ & $84,5 \%$ & $85,5 \%$ & $71,1 \%$ & $78,6 \%$ \\
\hline $\begin{array}{l}\text {-En otro lugar/Sin } \\
\text { especificar }\end{array}$ & $1,5 \%$ & $0,5 \%$ & $1,8 \%$ & $1,6 \%$ \\
\hline Total & $100 \%(387)$ & $100 \%(193)$ & $100 \%(470)$ & $\begin{array}{l}100 \% \\
(1050)\end{array}$ \\
\hline
\end{tabular}

Fuente: elaboración propia en base a información periodística extraída del diario "El Día".

Sin embargo, si observamos cómo se comportan estas variables en función de los distintos periodos presidenciales (tabla VII), surgen por lo menos dos particularidades. En primer lugar, resulta claro que es bajo la presidencia de Levingston donde las luchas expresan un menor grado de violencia material. Aunque pudiera resultar paradójico que esta circunstancia tenga lugar durante el gobierno más débil de los tres que se sucedieron bajo la "Revolución Argentina", y el que además mayores obstáculos encontró a la hora de plasmar sus iniciativas, sin embargo la debilidad en la capacidad de represión del gobierno podría explicar el escaso nivel de violencia material de los conflictos bajo su periodo.

Por el contrario, en momentos de consolidación del gobierno de Lanusse (y de su determinación de desarticular por medios represivos a los sectores y organizaciones que no se avenían a su plan de normalización), se observa un desplazamiento de la protesta estudiantil al combate callejero, que a su vez determinó que en varias ocasiones la ciudad estuviera sometida a severas medidas de seguridad, en las que se llegó a disponer también de la movilización de tropas del ejército, con las que se intentaba impedir manifestaciones obrero-estudiantiles. Más allá de estos operativos, el gobierno también intensifica su política represiva por medio de detenciones y allanamientos, que a su vez se convertirán en el eje de nuevas luchas estudiantiles. En este contexto de intensificación del accionar represivo, tienen lugar varios enfrentamientos, durante 1971 y principios de 1972, entre estudiantes y la policía, que se caracterizaran por el hecho de que en varias ocasiones las fuerzas de seguridad, pese a la violencia desplegada en la represión, no logran quebrar la resistencia estudiantil. Los manifestantes solían no sólo levantar barricadas con automóviles y otros elementos en amplias zonas de la ciudad, sino que en reiteradas oportunidades hacen uso de tácticas de hostigamientos y repliegues intermitentes, que conseguían desbordar a los efectivos policiales obligándolos a replegarse (Bonavena, 2012).

Por otro lado, los enfrentamientos en los que se hace algún uso de armas de fuego son proporcionalmente más importantes bajo la presidencia de Onganía (12,6\%); periodo en donde, como vimos previamente, las luchas acusan un menor grado de masividad (es decir, en donde en general las acciones son protagonizadas por grupos pequeños de personas). De manera que la mayor radicalidad en las formas evidenciada bajo la presidencia de Onganía no se corresponde necesariamente como una mayor masividad de las mismas. En términos generales los enfrentamientos materiales que incluyen cosas que pueden (o no) ser armas de fuego 
tienden a ser protagonizados, aún más que la media, por grupos intermedios (es decir grupos en los que participan de 50 a 500 personas), en detrimento de los grupos pequeños o más masivos (más de 500 personas).

Para complementar el panorama podríamos analizar otra de las variables que hemos utilizado para aproximarnos al nivel de radicalización de los enfrentamientos, es decir si las acciones se ubican dentro o fuera de los marcos que establecía el sistema institucional-legal y si en las mismas actúan solo las dirigencias o se evidencia un mayor involucramientos de cuerpos. En consonancia con lo que venimos analizando, en la figura VII se llega a visualizar cierta tendencia en las luchas del movimiento estudiantil a exceder los marcos de subordinación a las dirigencias o a las pautas marcadas por el sistema institucional legal. Si bien bajo todo el periodo 1969-1972 los conflictos estudiantiles que se desarrollan dentro del sistema institucional legal y en los que además solo hay presencia de cuadros dirigentes o militantes (es decir donde las dirigencias "operan solas", sin las bases) representan casi el 50\% de las acciones (49,8\%), dicho valor no solo es sensiblemente menor al que encontrábamos en el caso de los conflictos del movimiento obrero (70,5\%), sino que además presenta una dinámica decreciente a medida que nos acercamos al final de nuestra etapa de estudio.

TABLA VII

Formas que asume el enfrentamiento del movimiento estudiantil. Gran La Plata. 1969-1972.

\begin{tabular}{lllll}
\hline & \multicolumn{2}{c}{ Total } \\
\cline { 2 - 4 } & $\begin{array}{l}\text { Onganía } \\
84,6 \%\end{array}$ & $\begin{array}{l}\text { Levingston } \\
89,8 \%\end{array}$ & $\begin{array}{l}\text { Lanusse } \\
84,4 \%\end{array}$ & $85,4 \%$ \\
$\begin{array}{l}\text { Enfrentamiento material, } \\
\text { con cuerpos. }\end{array}$ & $2,7 \%$ & $8,3 \%$ & $6,5 \%$ & $5,7 \%$ \\
$\begin{array}{l}\text { Enfrentamiento material, } \\
\text { con cosas que no son }\end{array}$ & $12,6 \%$ & $1,9 \%$ & $9,1 \%$ & $8,9 \%$ \\
$\begin{array}{l}\text { armas de fuego } \\
\text { Enfrentamiento material, }\end{array}$ & $100 \%(182)$ & $100 \%(108)$ & $\begin{array}{l}100 \% \\
(340)\end{array}$ & $\begin{array}{l}100 \% \\
(630)^{*}\end{array}$ \\
\hline Total & & & & \\
\hline
\end{tabular}

Fuente: elaboración propia en base a información periodística extraída del diario

"El Día”. * De este total están excluidos los enfrentamientos verbales/escritos.

Por añadidura dicho declive se produce a costa tanto de las acciones que suceden dentro del sistema institucional legal pero con presencias de masas (que significan el 34,6\% del total), como de los hechos en los que se expresa un mayor involucramiento de los cuerpos en el conflicto y que se desarrollan por fuera del sistema institucional, que pasan del 10,6\% en el periodo de Onganía al 21,5\% bajo de la presidencia de Lanusse. Estas tendencias no estarían dando cuenta de un aspecto central en la dinámica del movimiento estudiantil: la diversidad de estrategias y trayectorias al interior del mismo, en tanto que los distintos sectores que lo conformaron se plantearon disimiles modalidades de acción y objetivos; aspecto que además se vuelve más patente hacia el final del periodo. Dicha circunstancia responde, en nuestra opinión, no solo a la diversidad de actores y tendencias políticas, sino que también estaría determinada por la doble táctica del gobierno. Durante la presidencia de Lanusse si bien se ensaya una salida política que implicaba no solo el pleno restablecimiento de las instituciones democráticas, sino también la intención de establecer un perfil más dialoguista en el ámbito específicamente universitario, paralelamente se intentaba mantener fuera de la legalidad a los sectores que no se avenían a su proyecto, aislando así a los sectores más radicalizados. 


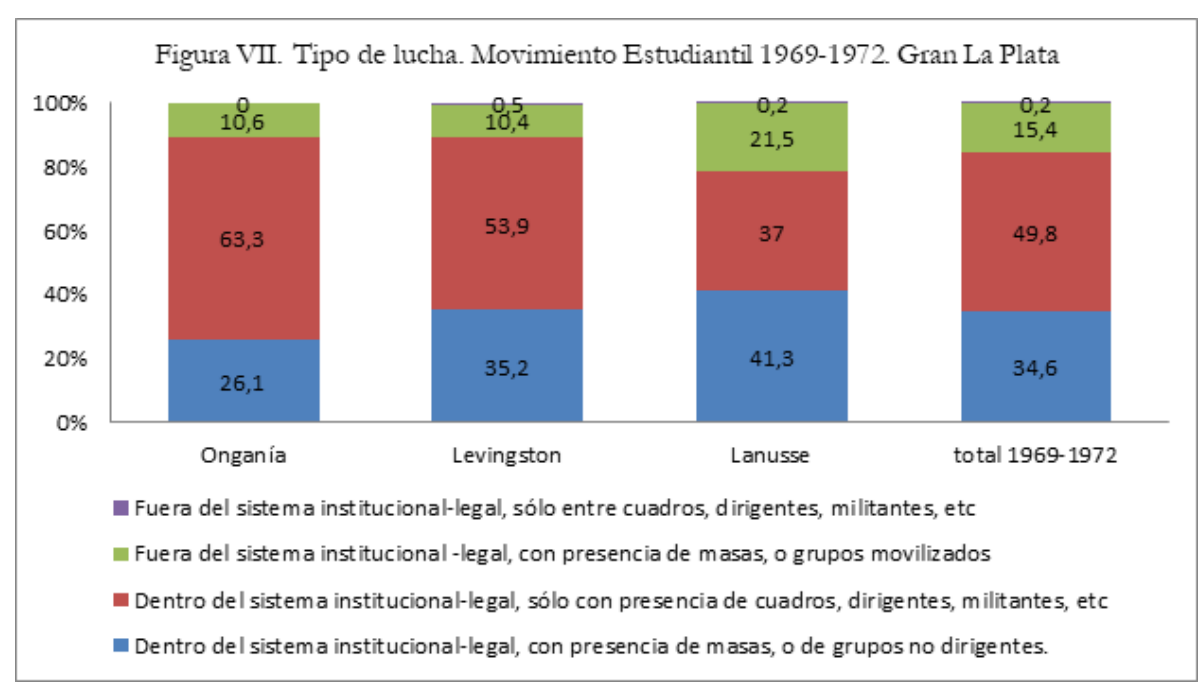

Fuente: elaboración propia en base a información periodística extraída del diario "El Día".

Un último aspecto de la conflictividad estudiantil que quisiéramos destacar es que además de desplegar una gran capacidad de lucha, evidenciada en su disposición a la lucha callejera, el movimiento estudiantil se caracterizó asimismo por presentar un mayor arraigo en su base social y una mayor predisposición a constituir alianzas con otros sectores sociales y políticos; destacándose entre ellos el movimiento obrero. Tales tendencias se desprenden de la lectura de los datos de la tabla VIII. Si bien en términos generales el porcentaje de las luchas en el que las dirigencias actúan solas (46,6\%) es similar al de las luchas que conllevan la movilización de las bases $(40,1 \%)$, la tendencia es a que este último tipo de lucha adquiera paulatinamente más importancia a mediada que nos acercamos al año 1972. El dato característico, sin embargo, es (independiente de que podamos considerarlo un signo de debilidad o fortaleza) la tendencia del movimiento estudiantil a componer fuerzas con los demás sectores sociales que se encontraban movilizados en la región.

Las acciones realizadas con otros sujetos, pertenezcan a la clase obrera o no, representan el 11,4\% del total, valor que duplica al que encontrábamos en el caso del movimiento obrero regional. Además este tipo de acciones se vuelven progresivamente más recurrentes hacia el final del periodo. En particular será 1971 uno de los momentos en donde los lazos con la clase obrera alcanzan mayor profundidad, en el marco de una de las grandes huelgas en aquella etapa: la de los obreros textiles de Petroquímica Sudamericana. ${ }^{42}$ Durante dicho periodo las acciones realizadas en conjunto entre el movimiento estudiantil y el movimiento obrero representan el $10,5 \%$ del total de conflictos estudiantiles, mientras que dicho valor para el año 1969 es del 6,1\%. Es decir que este tipo vínculos tuvo lugar entonces en momentos en que la protesta social en general se volvía más intensa. Recordemos que tanto para el movimiento obrero como para el estudiantil 1971 representaría el momento de mayor conflictividad. Sin embargo, hacia 1972 es tendencia a estrechar los vínculos se revierte. Por tanto, si la estrategia diseñada por Lanusse no logró que parte de la protesta estudiantil se canalizara por medio del sistema institucional, si logró de algún modo evitar o desarticular las alianzas que el movimiento estudiantil intentaba componer con otros sectores sociales. Por añadidura, debiéramos agregar que estas tendencias se desarrollaban en un contexto general, que como vimos anteriormente, se encuentra signado por una disminución del promedio diario de conflictos que se suma a una predisposición a que los mismos conflictos se desplacen del plano político. 
TABLA VIII

Principales actores. Movimiento estudiantil. Gran La Plata. 1969-1972.

\begin{tabular}{|c|c|c|c|c|c|}
\hline & & & & & \multirow[t]{2}{*}{ Total } \\
\hline & 1969 & 1970 & 1971 & 1972 & \\
\hline $\begin{array}{l}\text {-Dirigentes } \\
\text { estudiantiles. }\end{array}$ & $61,9 \%$ & $56,6 \%$ & $38.7 \%$ & $27,2 \%$ & $46,6 \%$ \\
\hline $\begin{array}{l}\text {-Militantes } \\
\text { estudiantiles, } \\
\text { asociaciones de base }\end{array}$ & $1,6 \%$ & $2,1 \%$ & $1,2 \%$ & $3,0 \%$ & $1,9 \%$ \\
\hline $\begin{array}{l}\text {-Estudiantes. (Incluye } \\
\text { dirigentes y cuadros } \\
\text { medios) }\end{array}$ & $27,5 \%$ & $35,5 \%$ & $44,6 \%$ & $54,5 \%$ & $40,1 \%$ \\
\hline -Obreros y estudiantes & $4,5 \%$ & $2,8 \%$ & $7,7 \%$ & $4,0 \%$ & $5 \%$ \\
\hline $\begin{array}{l}\text { - Estudiantes y fuerzas } \\
\text { sociales, profesionales, } \\
\text { políticas, población, } \\
\text { etc. }\end{array}$ & $2,9 \%$ & $2,1 \%$ & $5,0 \%$ & $8,4 \%$ & $4,4 \%$ \\
\hline $\begin{array}{l}\text { - Obreros, estudiantes, } \\
\text { y otras fuerzas } \\
\text { sociales, políticas, } \\
\text { profesionales, etc. }\end{array}$ & $1,6 \%$ & $0,7 \%$ & $2,8 \%$ & $3,0 \%$ & $2,0 \%$ \\
\hline Total & $100 \%(244)$ & $100 \%(281)$ & $100 \%(323)$ & $\begin{array}{l}100 \% \\
(202)\end{array}$ & $\begin{array}{l}100 \% \\
(1050)\end{array}$ \\
\hline
\end{tabular}

Fuente: elaboración propia en base a información periodística extraída del diario "El Día”.

\section{CoNCLUSIÓN}

Si uno de los objetivos que se propuso la dictadura militar instaurada en 1966 fue el de amoldar las universidades y el movimiento estudiantil a su proyecto político autoritario, claramente podríamos sostener que fracasó en sus propósitos. Más aún, resulta indudable que el intento por parte de la "Revolución Argentina" de reconfigurar el régimen universitario ofició de catalizador de la protesta de un ya movilizado y politizado movimiento estudiantil, en un contexto signado por el crecimiento de la matrícula universitaria, incluso a un ritmo muy superior al crecimiento vegetativo de la población. En nuestro caso de estudio pudimos observar como en el marco de reivindicaciones de carácter tanto corporativo como político, el movimiento estudiantil platense inició un ciclo de luchas en las que se acusa un alto nivel de radicalidad y combatividad, en un enfrentamiento con la dictadura que adquirió por momentos un carácter frontal. De todos maneras, como pudimos observar ni las dinámicas de este ciclo de luchas del movimiento estudiantil fueron lineales, ni las características de sus enfrentamientos homogéneas.

En primer término, porque a lo largo del periodo la intensidad de las luchas, desde el punto de vista cuantitativo, presentaron una tendencia muy marcada, acompañando en parte las divisadas para el caso del movimiento obrero tanto regional como nacional. Desde 1969 las luchas del movimiento estudiantil se intensificaron, alcanzando el momento de mayor magnitud en el año 1971. Sin embargo, en un contexto sensiblemente distinto, marcado particularmente por la política del GAN, la conflictividad estudiantil acusará un importante declive hacia el año 1972, aunque ello no significó una disminución en el grado de masividad de la protesta. Asimismo, encontramos que al interior de esta tendencia, las luchas del movimiento estudiantil tuvieron la particularidad de acusar un comportamiento más bien cíclico y estacional.

Más allá de esta sucesión de tendencias ascendentes y descendentes, del análisis realizado se desprendió que el movimiento estudiantil platense se caracterizó no solo por haberse expresado en formas de luchas que dieron cuenta de importantes grados de masividad, sino también de considerables niveles de combatividad 
y de radicalización política, en particular si es contrastado con las tendencias registradas para el caso del movimiento obrero regional. El movimiento estudiantil logró, de algún modo, articular las demandas más corporativas o circunscriptas a cada facultad a un movimiento antidictatorial.

Este aspecto que estamos resaltando daría cuenta de una característica más general y estructural de los movimientos estudiantiles, por lo menos durante las décadas del sesenta y del setenta, referida a la mayor fluidez con las que las reivindicaciones y demandas de orden corporativo derivan en un cuestionamiento más global del orden político y económico nacional. ${ }^{43}$

En nuestro caso fue fundamentalmente la lucha contra el limitacionismo y por la expansión del sistema universitario las que se convirtieron, del algún modo, en el eje alrededor del cual se motorizó en un principio la movilización estudiantil. Esta lucha emprendida por el movimiento estudiantil logró de alguna manera superar algunos de los puntos más cuestionados de la ley universitaria, tales como los aranceles y las materias topes o morigerar el carácter limitacionista de los cursos de ingreso. Sin embargo, dichos reclamos corporativos se subsumieron rápidamente en demandas sociales y políticas que excedían los estrechos marcos del mundo académico. La impugnación a la política represiva del régimen y la protesta en contra de las medidas "limitacionistas" fueron centrales en impulsar la movilización de los estudiantes. Si uno de los objetivos de la dictadura militar fue la de obstaculizar el proceso de politización creciente que la vida universitaria evidenciaba durante la década del sesenta, claramente su resultado fue un fracaso. Más aún, podríamos sostener que fue justamente la tónica autoritaria del gobierno y su intento de controlar férreamente a la sociedad la derivó en que las luchas del movimiento estudiantil adquirieran por momentos rasgos antiregimen o antiestatales.

La centralidad que tuvieron las luchas para revertir el cercenamiento de las conquistas y derechos obtenidos en los años previos, da cuenta de otra de las características que presentó el movimiento estudiantil platense. Ya sea que nos enfoquemos en las formas organizativas como en las tendencias políticos-ideológicas encontramos cierta predominancia de los actores tradicionales o clásicos del movimiento estudiantil argentino. Los sectores reformistas conservaron una importancia muy marcada dentro de la militancia estudiantil en la UNLP, llegando a ser un sujeto central de la activa y sostenida militancia universitaria radicalizada que se enfrentó firmemente contra la dictadura militar. En este sentido, estaríamos tentados a no circunscribir la radicalización del estudiantado al proceso de "peronización", sino más bien vincularlo a una reconfiguración de la tradición reformista, que en tanto identidad política del movimiento estudiantil, sufre un proceso de resignificación y mutación (Califa, 2014), en el marco de un régimen dictatorial fuertemente represivo. Elementos como la generalización del uso de la violencia en las acciones estudiantiles, la solidaridad obrero-estudiantil y la lucha antiimperialista, generalmente asociados al peronismo, no fueron, en modo alguno, extraños a los sectores reformistas. ${ }^{44}$ Por otro lado, las corrientes peronistas no fueron las mayoritarias ni las más activas, por lo menos hasta el año 1972, momento en el que, sugestivamente, las luchas de orden gremial adquieren una mayor centralidad. Esta tendencia afecta también al reformismo, lo que se expresará en el crecimiento de sus variantes más liberales.

Como decíamos, hacia el año 1972, es decir en el marco de un momento político y social diferente al de los años previos, los reclamos corporativos predominaron con respecto a los de orden político, que fueron determinantes a la hora de explicar gran parte de la dinámica de la protesta estudiantil en La Plata. En verdad, esta tendencia que puede observarse hacia el año 1972 refleja, en nuestra opinión, algunos de los resultados que arrojaba la estrategia diseñada por Lanusse a través del GAN. La reaparición de los partidos políticos, mientras se forjaba un perfil más dialoguista e institucionalista de las autoridades universitarias ${ }^{45}$, determinó que las instancias de representación del movimiento estudiantil tendieran a articular cada vez los intereses más corporativos y directos de su base social.

De todos modos, tal como hemos podido advertir a lo largo del capítulo, independientemente de esta tendencia a que los reclamos del movimiento estudiantil se "despoliticen" hacia el año 1972, la estrategia del GAN no logra, por lo menos en ciertos sectores del movimiento estudiantil platense, que los enfrentamientos 
se canalizaran cada vez más dentro de los marcos institucionales legales, ni tampoco que las acciones perdieran masividad. Quizá una de las particularidades, en términos generales, que presentó el movimiento estudiantil platense fue la capacidad evidenciada en sus enfrentamientos para otorgarles a los mismos un importante grado de violencia material, que resultaron cada vez más acentuados, a pesar de las intenciones oficiales hacia finales de nuestro periodo de estudio de institucionalizar la conflictividad por medios "normales" y "razonables". De manera recurrente las protestas motorizadas por algunos sectores del movimiento estudiantil derivaron en intensos enfrentamientos callejeros con la policía, que adquirieron cada vez mayor violencia.

En muchas ocasiones, como sostuvimos, fue la propia intervención represiva la que determinó la radicalización de la protesta estudiantil, que por añadidura se convirtió en un punto focal de la oposición de amplios sectores de la sociedad civil al autoritarismo del gobierno. No obstante, a la par que esta táctica del gobierno le permite al movimiento estudiantil sumar alianzas con fracciones de otras clases y radicalizar el enfrentamiento, ofició en el largo plazo de obstáculo para los procesos de organización y lucha, al tiempo que resintió los grados de unidad hacia el interior del movimiento estudiantil. Aspecto este último que se hace evidente en las diferentes modalidades de acción y objetivos que se desarrollaron al interior del movimiento estudiantil.

Esta diversidad de trayectorias y dinámicas que pueden observarse para el caso del movimiento estudiantil platense en verdad pude ser expresivo de una característica más estructural del mismo señalada por Sánchez Aranda. Para este autor, la conflictividad del movimiento estudiantil...

"Por lo general es un detonador del descontento y multiplicador de otros movimientos, ya que tiene la capacidad de provocar, entusiasmar y motivar la movilización de obreros y otros sectores, y se va dando un acercamiento con el pueblo y sus luchas, así que contribuye a la politización de la sociedad. Sin embargo, por la misma lógica del estudiantado y lo coyuntural de sus movilizaciones, presenta una oleada, flujo y reflujo, que sin ser exclusivos de los movimientos estudiantiles, sí es una pauta general estrechamente relacionada con las condiciones y potencialidades del movimiento" (Sánchez Aranda, 2000: 247)

A lo largo de nuestro trabajo pudimos apreciar que más allá del importante grado de combatividad y politización que evidenció el movimiento estudiantil local, junto a los denodados esfuerzos por vincular sus luchas con la de los demás sectores sociales, no obstante no pudo superar ciertos obstáculos en la consecución de sus objetivos a más largo plazo.

\section{BibLIOgRAFía}

Altamirano, C. (2001) Bajo el signo de las masas (1943 - 1973). Buenos Aires: Ariel Historia.

Alessandro J. (2011) La colina táctica del enemigo. Un recorrido por el pensamiento y la militancia de los universitarios platenses (1950/75). La Plata: De la campana.

Aranda Sánchez, JM (2000) “El movimiento estudiantil y la teoría de los movimientos sociales” en: Convergencia. Revista de Ciencias Sociales. Universidad Autónoma del Estado de México.

Barletta, A (2001) "Peronización de los universitarios (1966 - 1973) Elementos para rastrear la constitución de una política universitaria peronista”. En: Pensamiento Universitario n ${ }^{\circ} 9$.

Balvé, B. y Balvé, B. (2005) El '69. Huelga politica de masas, Buenos Aires: Ediciones ryr-CICSO.

Bonavena, P (2014) “Aprovechando la coyuntura política: la protesta de los estudiantes de Kinesiología de la UBA en las postrimerías de la dictadura encabezada por Alejandro Lanusse” en: Millán, M (comp) Universidad, politica y movimiento estudiantil en Argentina, entre la Revolución Libertadora y la democracia del '83. Buenos Aires: Final Abierto.

Bonavena, P. (2012) "Conflicto social y protesta en la ciudad de La Plata: el caso del movimiento estudiantil frente a la irrupción de la 'Revolución Argentina'” en: Castillo, C y Raimundo, M (Comps.) El '69 Platense. Luchas obreras, conflictos estudiantiles y militancia de izquierda en La Plata, Berisso y Ensenada durante la Revolución Argentina. Buenos Aires. Estudios Sociológicos Editora. 
Trabajos y Comunicaciones, 2da. Época, № 48, e066, julio-diciembre 2018. ISSN 2346-8971

Bonavena, P. (2012b) “¿Centros de estudiantes o cuerpos de delegados? Las experiencias de los Cuerpos de Delegados de las Facultades de Derecho y Arquitectura de la UBA y en las Escuelas de Bellas Artes Prilidiano Pueyrredón y Manuel Belgrano en 1971". Buenos Aires.

Bonavena, P. y Millán, M. (2010) "La lucha del Movimiento Estudiantil cordobés por el ingreso irrestricto a la Universidad en 1970 y 1971" en Vidal, G y Blanco, J (coord.) (2010) Estudios de la historia de Córdoba en el siglo $X X$. Tomo II. Córdoba: Ferreyra.

Bonavena, P. (2006) "El movimiento estudiantil de la ciudad de La Plata (1966-1973)" en: Cuestiones de sociologias N 3. La Plata: Prometeo Libros.

Bonavena, P. y otros, (1998) Origenes y desarrollo de la guerra civil en la Argentina.1966-1976, Buenos Aires: Eudeba. Buchbinder P. (2005) Historia de las Universidades Argentinas. Buenos Aires: Sudamericana

Califa, J (2014) "Obreros y estudiantes, ęunidos y adelante? Los estudiantes de la Universidad de Buenos Aires frente al movimiento obrero bajo la 'Revolución Argentina', 1966-1973” en: Archivos de historia del movimiento obrero y la izquierda. Buenos Aires, Año IV, No8, marzo de 2016.

Califa, J. (2016) Reforma y Revolución. La radicalización politica del movimiento estudiantil de la UBA 1943-1966, Buenos Aires: Eudeba.

De Luca, R (2006) “La Reforma educativa de Onganía. El tercer momento de una estrategia”. En: Razón y Revolución, $n^{\circ}$ 15, Buenos Aires, 1er. semestre de 2006, pp. 165-182.

Ghigliani, P (2009) "Acerca de los estudios cuantitativos sobre conflictos laborales en Argentina (1973-2009): reflexiones sobre sus premisas teórico-metodológicas” En: Conflicto Social, Año 2, $N^{\circ}$ 2. Disponible en: http:// www.webiigg.sociales.uba.ar/conflictosocial/revista/02/005_ghigliani.

Graciarena, J (1971) “Clases medias y movimiento estudiantil. El Reformismo Argentino 1918-1966”, en Revista Mexicana de Sociología, Año 33, N 1. Instituto de Investigaciones Sociológicas, UNAM, México.

Izaguirre, I y Aristizabal, Z. (2002), Las luchas obreras 1973 - 1976. Documento de trabajo №17, Buenos Aires, Instituto de Investigación Gino Germani. Facultad de Ciencias Sociales. UBA.

Jacoby, R (1978) Conciencia de clase y enfrentamientos sociales: Argentina 1969. Buenos Aires. Cuaderno de CICSO. Serie estudios No 32.

Korzeniewicz, R. P. (1995). Labor unrest in Argentina, 1906-90. Review XVIII, 105-16

Lanteri, M (2009). “'Los pasos previos. El largo proceso de conformación de la JUP en la Universidad Nacional de La Plata (1960-1973)'”. En XII Jornadas Interescuelas/ Departamentos de Historia. Bariloche.

López Sánchez, R (2005) "Fundamentos teóricos para el estudio de los movimientos estudiantiles en Venezuela" en Espacio Abierto Cuaderno Venezolano de sociología. Vol. 14 No 4.

Marini, R. M. (1970) "Los movimientos estudiantiles en América Latina” en Ciencia social. Instituto Central de Sociología. Consejo de Difusión Universitaria. Universidad de Concepción - Chile.

Mignone, E. (1998) Politica y universidad. El estado legislador. Buenos Aires: Lugar Editorial.

Millán, M. (2011) "Radicalización y peronización estudiantil durante la 'Revolución Argentina' (1966-1971)”. Un examen crítico a la luz de los casos de Rosario y el Nordeste". En: Alcira Daroqui [et. al.] IX Jornadas de Sociología de la UBA. Buenos Aires: UBA.

Nava, A. (2017) Protesta social y conflictividad laboral. Estrategias del movimiento obrero en La Plata, Berisso y Ensenada (1969-1972). Facultad de Humanidades y Ciencias de la Educación. UNLP.

Nava, A.(2013) "Radicalización y politización del movimiento estudiantil: el caso platense durante la 'Revolución Argentina'. 1966-1972”. En: Revista Conflicto Social. Año 6 No 9. Enero a junio de 2013. Disponible en línea: http://webiigg.sociales.uba.ar/conflictosocial/revista/09/08_A.Nava.pdf

Nava, A. y ROMÁ, P. (2011) “Algunos apuntes para el estudio del movimiento obrero-estudiantil en La Plata, Berisso y Ensenada durante las décadas del sesenta y setenta” en Revista Conflicto Social. Año 4, No5. Junio de 2011.

O 'Donnell, G. (2009) El Estado Burocrático Autoritario, 1966-1973, Buenos Aires: Prometeo Libros.

Portantiero, J C, (2014 [1971]): “Estudiantes y Populismo" en Tortti (dir.) La nueva izquierda argentina (1955-1976): socialismo, peronismo y revolución, Rosario: Prohistoria. 
Portantiero, JC. (1978) Estudiantes y politica en América Latina. México: Siglo XXI.

Pis Diez, N. (2014) Universidad y politica en el postperonismo : El caso de la Universidad Nacional de La Plata y su movimiento estudiantil (1955-1966). Un estado de la cuestión (En línea). Trabajo presentado en VIII Jornadas de Sociología de la UNLP, 3 al 5 de diciembre de 2014, Ensenada, Argentina. Disponible en: http:// www.memoria.fahce.unlp.edu.ar/trab_eventos/ev.4328/ev.4328.pdf

Pis Diez, N.(2017) "Compañero trabajador, no falte! El movimiento reformista de La Plata y la unidad obreroestudiantil en los tempranos sesenta: acciones por una vieja bandera" en Revista de la Red de Intercátedras de Historia de América Latina Contemporánea; Córdoba; Año: 2017 p. 99 - 114.

Robles, H. (2011) Radicalización politica y sectores populares en la Argentina de los '70 : La juventud peronista y su articulación con Montoneros en los barrios periféricos de la ciudad de La Plata (Tesis de posgrado). Presentada en Universidad Nacional de La Plata. Facultad de Humanidades y Ciencias de la Educación para optar al grado de Magíster en Ciencias Sociales. Disponible en: http://www.memoria.fahce.unlp.edu.ar/tesis/te.437/te.437.pdf.

Seia, G. (2014) "La lucha del movimiento estudiantil por el ingreso directo: Una aproximación al caso de la Universidad de Buenos Aires entre 1969 - 1973” en Millán, M (comp) Universidad, politica y movimiento estudiantil en la Argentina (entre la "Revolución Libertadora" y la democracia del '83). Buenos Aires: Final Abierto.

Sigal, S. (1991) Intelectuales y poder en la década del sesenta. Buenos Aires: Puntosur.

Simonetti, M. F. (2002). Tocar el cielo con las manos. La actividad política de la FURN en la UNLP durante 1966-1973. Tesina de Grado. La Plata: Dto. de Sociología (FaHCE/UNLP) en CD.

Suasnábar, C. (2004) Universidad e intelectuales: educación y politica en Argentina 1955-1976. Buenos Aires: Manantial.

Terán, O. (2013), Nuestros años sesentas. La formación de la nueva izquierda intelectual argentina, 1956-1966. Buenos Aires: Siglo XXI

Tortti, M. C. (2006) "La nueva izquierda en la historia reciente de la Argentina”, en Cuestiones de Sociología, N³, Buenos Aires, Otoño 2006.

Vega, N. (2014) "La política universitaria del Onganiato. El caso de la Universidad Nacional del Litoral" en $2^{\circ}$ Jornadas de Ciencia Politica del Litoral. Universidad Nacional del Litoral- 29 y 30 de Mayo de 2014. En línea: http://www.fhuc.unl.edu.ar/materiales_congresos/cienciapolitica_2014/pdf/3)\%20Teoria, \%20Filosofia\%20e\%20Historica\%20Politica/Vega.pdf

\section{FuENTES}

Diario El Día, La Plata. Edición del 01/01/1969 al 31/12/1972

\section{Notas}

1 Gran parte de los autores suelen señalar que bajo nuestro periodo de análisis estaríamos en presencia de una clara tendencia a la unificación de las luchas del movimiento obrero y del movimiento estudiantil. Sin embargo, los vínculos entre ambos sujetos no dejaron de ser problemáticos. Esta circunstancia ha dado lugar a cierto debate respecto a las características propias que tuvo esta relación en la historia reciente argentina. Respecto a las distintas posturas en este debate puede verse Terán (2013); Graciarena (1971), Portantiero (2014 [1971]) y Califa (2016). Si bien en este trabajo vamos a poner en tensión las dinámicas de las luchas de ambos sujetos desde el punto de vista cuantitativo, no nos adentraremos en este debate que ameritaría un análisis en mayor profundidad.

2 La elección del diario "El Día” está en función de que, al ser un periódico provincial, con asiento en la misma ciudad de La Plata, dedicaba una parte importante de su edición al acontecer político y social de la propia ciudad. Por añadidura, por su propio carácter regional el diario no solo funcionaba en su carácter informativo o editorialista, sino también como medio a través del cual muchas organizaciones, sindicatos, partidos políticos, empresarios, publicitaban distintos eventos, hechos, opiniones puntuales, etc. A partir de todos estos registros hemos elaborados nuestra base de datos cuantitativa. De todos modos, deberíamos tener en cuenta que si bien los periódicos, en términos generales, nos informan sobre una amplia variedad de formas y protagonistas en las que se manifiesta la conflictividad social, es evidente y obvio que no 
da cuenta de toda la conflictividad realmente existente. De manera que, la primera prevención a tener en cuenta es que, como señala Ghigliani (2009), los guarismos que se desprenden del análisis cuantitativo tienen más valor con respecto a las tendencias que se hacen observables a partir de las distintas dimensiones y variables de análisis, que a la recurrencia real de conflictos o huelgas registradas

3 En la medida en que nuestro objetivo es poder captar la mayor variedad de tipos de conflictos y de sujetos que protagonizan los mismos, hemos optamos por una definición amplia de conflicto. De esta manera, nuestra unidad de análisis no se circunscribe a las manifestaciones más disruptivas de la conflictividad (como podrían ser los paros o manifestaciones callejeras), que, si bien son centrales, no agotan por sí mismas la complejidad del accionar gremial y político del movimiento estudiantil.

4 Sobre la dinámica y militancia del movimiento estudiantil platense previo a nuestro periodo pueden verse Bonavena (2006) y Nayla Pis Diez (2014)

5 Este dato corresponde al año 1966. Información extraída de Balvé, Beba y Balvé, Beatriz, (2005). Para el año 1972 la cifra ascendía a 43800 (El Día, 5/11/72).

6 Según los datos aportados por Buchbinder, la matrícula universitaria argentina habría crecido de 159.000 en 1960 a los 333.000 alumnos en 1972 (Buchbinder, 2010: 194). En el caso de la UNLP, la matrícula había crecido en un 51 por ciento entre 1966 a 1972, ya que, como vimos en la nota anterior, había pasado de 29000 alumnos a 43886 en el último de los años. Dicha matrícula se encontraba distribuida entre las distintas facultades del siguiente modo: Ciencias Médicas: 9517; Humanidades y Ciencias de la Educación: 6968; Ingeniería: 5400; Ciencias Económicas: 4895; Ciencias Jurídicas: 4800; Ciencias Exactas: 2301; Ciencias Veterinarias: 1956; Arquitectura y Urbanismo: 1850; Bellas Artes: 1434; Ciencias Naturales: 1350; Agronomía: 1417; Escuela de Odontología: 1333; Escuela de Periodismo: 442; Observatorio 111; Escuela de Bibliotecarios: 92 (El Día, 5/11/72).

7 Si bien refiere a otro tipo de discusión, pensamos que en parte este discurso de algunos sectores del poder político y de las Fuerzas Armadas visualizando a las universidades como centros de infiltración comunista y revolucionaria, se encontraba de algún modo sobredeterminado por la doctrina de seguridad interna desarrollada en el contexto de la guerra fría.

8 En el caso de la UNLP, los centros de estudiantes siguieron teniendo actividad y celebrando elecciones (aunque con intermitencias) durante toda la etapa 1966-1972. Dicho funcionamiento se daba, sin embargo, de manera no oficial, es decir sin el reconocimiento de la representatividad estatutaria, de la que gozaban previamente.

9 La norma establecía que los nuevos consejos académicos serían elegidos por el voto exclusivo de los profesores ordinarios, quedando excluido no solo el claustro estudiantil sino también los graduados. Los estudiantes podían ser representados por un delegado en las sesiones de los consejos académicos, aunque no pudiendo gozar del derecho a voto.

10 La actitud del claustro de profesores de mantenerse en sus cargos estaba pensada como parte de una estrategia, compartida en un primer momento por la FULP, de resistencia interna a la intervención, con lo cual la inexistencia de renuncias no implicaba necesariamente una aceptación del nuevo ordenamiento universitario. Independientemente de significar una táctica de resistencia desde adentro, implicaba no obstante en algunos casos más una adaptación pasiva al nuevo "estado de situación" imperante (Buchbinder 2010:191).

Uno de los problemas que aquejaban al sistema universitario, según el diagnóstico elaborado por las Fuerzas Armadas, era el crecimiento desmedido de la matrícula y la alta tasa de deserción (De Luca, 2006).

11 La actitud del claustro de profesores de mantenerse en sus cargos estaba pensada como parte de una estrategia, compartida en un primer momento por la FULP, de resistencia interna a la intervención, con lo cual la inexistencia de renuncias no implicaba necesariamente una aceptación del nuevo ordenamiento universitario. Independientemente de significar una táctica de resistencia desde adentro, implicaba no obstante en algunos casos más una adaptación pasiva al nuevo "estado de situación" imperante (Buchbinder 2010:191).

12 La ambigüedad a la que estamos haciendo alusión, en verdad, respondía a que, según lo dictaminaba la ley 17245 todavía vigente, los cursos de ingreso eran obligatorio en todas las Universidades Nacionales del país. La intención, en este caso, por parte de las autoridades universitarias de la UNLP era aminorar el carácter "limitativo" de los mismos. Medidas similares, o aún más drásticas, son adoptadas sin embargo, por algunos rectores de otras universidades nacionales. Por ejemplo, el rector de la alta casa de estudios de Córdoba (Ghirardi) decide, a principios de 1971, dejar sin efecto las pruebas obligatorias de ingreso a las facultades (El Día, 04/03/1971); a pesar de que el Ministro de Cultura y Educación de ese momento (José Luis Cantini) ratificara públicamente la vigencia de las mismas.

13 A pesar de que Lanusse aumenta las partidas presupuestarias destinas a las Universidades Nacionales, la cuestión presupuestaria no deja de ser un motivo de queja recurrente en el ámbito académico.

14 A este cuadro de situación deberíamos agregar además la tendencia a la creciente proletarización de las consideradas profesiones liberales que tensionaba en algún punto su situación en el mercado laboral. Entre los autores que hacen hincapié en este aspecto podríamos citar Portantiero (1978) y Ruy Mauro Marini (1970).

15 Esta misma curva en forma de U invertida también puede divisarse para el caso del movimiento obrero en el plano nacional, si tenemos en cuenta los datos brindados por O’Donnell (2009: 394) o por Korzeniwicz (1995). Para el caso del movimiento obrero del Gran La Plata véase Nava (2017) y figura II. En lo que respecta al movimiento estudiantil 
platense, Pablo Bonavena encuentra la misma tendencia, aunque para una unidad de análisis más acotada que la nuestra: acciones de masa, es decir “....acciones por fuera del marco institucional como ocupaciones de edificios, huelgas, actos, marchas y varias formas de lucha callejera” (Bonavena, 2012: 170). Este autor contabiliza para el año 1969103 acciones, en 1970 105, en 1971141 y en 197297.

16 Diversos autores han marcado la centralidad que tuvieron las luchas por el ingreso irrestricto en otras universidades. Para el caso de la UBA véase Bonavena (2012b) y Seia (2014). En el caso de la Universidad de Córdoba véase Bonavena y Millán (2010).

17 Si bien los acontecimientos que tuvieron lugar durante el mes de mayo de 1969 en estas tres ciudades han sido analizados por una numerosa bibliografía, un análisis pormenorizado y en profundidad de los mismos puede encontrarse en Jacoby (1978).

18 Estudiante cordobés asesinado por la policía en el marco de una creciente conflictividad estudiantil en la ciudad de Córdoba durante el mes de septiembre de 1966.

19 Es decir, la misma cantidad que durante el mismo mes del año anterior.

20 Estos tres estudiantes habían sido asesinados por las fuerzas de seguridad en el marco de las protesta del mes de mayo de 1969 en las ciudades de Corrientes y Rosario.

21 Este sería el único momento en el que los momentos de alza en la conflictividad de ambos sujetos coincide en el tiempo. Salvo en el caso del mes de junio de 1971, los picos mensuales de conflictividad del movimiento estudiantil no se corresponden con los del movimiento obrero.

22 Dicha distinción presenta como inconveniente el hecho de que no da cuenta cabal de los distintos grados de protagonismo e inserción de las diversas corrientes político-estudiantiles, ya que además éstas participaban en la conducción de los centros de estudiantes. De todos modos, la alternancia entre las distintas corrientes políticas en la conducción de estas instancias no nos permite establecer un análisis conjunto, de manera que daremos cuenta de un panorama aproximado del mapa político del movimiento estudiantil, el cual debería ser profundizado por medio de un análisis cualitativo.

23 Este total no coincide con el que veníamos utilizando (1050), ya que este último incluía todas las acciones en las que participaba algún sujeto estudiantil, aunque los mismos no tuvieran la iniciativa. En el caso que nos atañe estamos analizando la adscripción política institucional de las acciones en las que el movimiento estudiantil tienen la iniciativa.

24 Claramente esta distinción organizativa determina que ambas impulsen luchas de distinto carácter. Mientras los Centros en particular tienen la iniciativa fundamentalmente en las luchas por reivindicaciones corporativas (el 86,6\% de sus acciones se corresponde a este tipo de lucha), por el contrario las tendencias y federaciones serán las encargadas de motorizar las luchas de orden político.

25 Aspecto que se vuelve aún más notorio si tenemos en cuenta la escaza actividad que presentan los casos de Ciencias Naturales y Arquitectura (véase tabla IV), en donde en lugar de los clásicos centro de estudiantes, las estructuras directivas estaban conformadas por medio de Comisiones por Carrera y Delegados de Curso, en general alineadas con las tendencias políticas de izquierda y combativas. En la tabla VIII más adelante puede observarse también que el control del movimiento estudiantil por parte de las instancias clásicas de representación, tales como centros y federaciones, no parece haber sido cuestionado seriamente por otro tipo de organización más horizontal, como lo fueron las Comisiones por Carreras o Cuerpos de Delegados, que tuvieron una participación marginal $(1,9 \%)$ en los conflictos desarrollados durante 1969-1972.

26 El reformismo en tanto movimiento presentaba unos límites ideológicos no demasiado precisos, lo que permitía que convivieran en su seno posiciones y fuerzas diversas. No obstante esta pluralidad, como sostiene Sigal (1991), la identidad reformista universitaria se caracterizaba por una reivindicación de la autonomía universitaria y del monopolio estatal de la enseñanza (laica y gratuita), exigencia que iba unida a la aspiración de replicar en el marco de la Universidad el modelo político democrático. Todo esto articulado a una identidad política progresista, que le otorgaba a la universidad un papel central en el proceso de transformación de la sociedad.

27 El FAUDI surge del proceso de crisis y ruptura en la que se encontraba el PCA (Partido Comunista Argentino), y que deriva en la conformación del denominado "Comité Nacional de Recuperación Revolucionaria- PC" luego convertida en PCR (Partido Comunista Revolucionario) en 1968. Finalmente este último grupo conforma en el ámbito universitario el FAUDI. Al igual que FM, esta tendencia sostenía reclamos de tono reformistas como la autonomía y el cogobierno, un mayor presupuesto, etc, aunque desde una posición política más radical.

28 De algún modo, la preeminencia que ya había ganado FM y la FULP hacia 1970 empieza a ser discutida al año siguiente con motivo de ciertas divergencias y disidencias que comienzan a surgir en el seno de FM y que culminan con varias divisiones. En verdad a lo que asistimos es a un proceso por el cual FM deja de ser una agrupación que expresaba la alianza entre distintas tendencias políticas (entre las que se encontraban los radicales, algunos grupos anarquistas y socialistas), para ir convirtiéndose de manera paulatina en el brazo del radicalismo en el ámbito universitario

29 Para un análisis en mayor profundidad de esta corriente puede verse Simonetti (2002), Lanteri (2009) y Alessandro (2011). 
30 La otra tendencia peronista con presencia en nuestra región era el Frente de Agrupaciones Eva Perón (1971), aunque como se puede ver en la tabla III tiene una actividad en la conflictividad bastante marginal.

31 En el caso del Centro de Estudiantes de Derecho la conducción del mismo fue ejercida ininterrumpidamente durante nuestro periodo por la agrupación FM. En Humanidades, el FAUDI presentaba un dominio absoluto sobre dicho centro, aunque momentáneamente perdió la conducción a manos de FM durante el año 1970. El FAUDI también tenía cierto dominio indiscutido sobre la conducción del Centro de Estudiantes de Ciencias Médicas, sin embargo a fines de 1972, y en contexto general de retroceso de dicha tendencia, lo perderá en mano de una agrupación del MOR. En Ciencias Económicas la agrupación FM controlaba el Centro de Estudiantes aunque a finales de la etapa el proceso de fragmentación y división que afectaba a dicha agrupación repercutió en la actividad de dicho centro de estudiantes.

32 Si bien en 1969 la lista Ateneo de Veterinarias se disuelve, el dominio lo continúan ejerciendo agrupaciones (Cruz Violeta y Agrupación Autónoma de Estudiantes de Veterinaria) que eran desprendimientos de ella.

33 Este caso que estamos citando nos advertiría sobre una problemática en particular que, por razones de espacio, no podemos profundizar. Nos estamos refiriendo a la circunstancia de que no siempre la ausencia de conflictividad supone necesariamente una debilidad en el poder que presentan determinados sujetos para realizar sus intereses en el marco de las relaciones que establecen con sus oponentes.

34 La multiplicidad de objetivos explícitos y específicos por los cuales se inician las distintas acciones las hemos agrupados a través de tres categorías: a) "lucha gremial corporativa", en las que se incluyen todas las luchas cuyas reivindicaciones se encuentran específicamente vinculadas o acotadas al ámbito universitario o estudiantil más inmediato; b) "conflicto intraestudiantil”. Con esta categoría, hemos intentado captar los enfrentamientos dentro del mismo movimiento estudiantil, ya sea al interior de un Centro de Estudiantes o entre distintas tendencias. Y en tercer lugar, c) "luchas extragremiales", que agrupa a todas aquellas luchas que tienen como objetivo aspectos que exceden la inmediatez de lo corporativo y se ubican en un terreno más netamente político.

35 En el caso del movimiento obrero, casi dos tercios de los conflictos laborales de la etapa 1969-1972 se refirieron específicamente a luchas de carácter económico- corporativo $(64,9 \%)$, seguidas, en orden de importancia, por las luchas extra gremial-corporativas $(27,5 \%)$ y en última instancia, por los conflictos intragremiales $(7,5 \%)$.

36 Además de la obligatoriedad y la generalización de los cursos y exámenes de ingreso eliminatorios o selectivos, la ofensiva limitacionista se materializaba por medio de la supresión de las correlatividades, el establecimiento de aranceles y multas por aplazos y recuperación de trabajos prácticos, la liquidación de los turnos mensuales de exámenes y los recuperatorios de trabajos prácticos y parciales, el aumento de las horas de cursada obligatorias, la reducción de los servicios sociales que brindada la comunidad (entre ellos el comedor universitario), etc.

37 Por su parte, los conflictos al interior del movimiento estudiantil alcanzan su mayor valor durante la presidencia de Levingston. Aunque habría que tener en cuenta que hacia fines de 1970, la mayoría de los centros de estudiantes convocaron a elecciones para renovar las conducciones, que concitaron particular atención, ya que muchos de ellos no realizaban elecciones desde hacía algunos años.

38 Siguiendo en parte el análisis que realizan Izaguirre y Aristizabal (2002), como sosteníamos hemos decidido agrupar los fines en tres categorías: rechazo formal/en disputa; a favor del régimen militar y contra el régimen militar. En esta última categoría se incluyeron todos los enfrentamientos en los cuales se expresaba un rechazo sustancial y directo al programa económico, político y social que llevaba adelante la dictadura militar durante aquellos años, propugnando además la modificación esencial del mismo independientemente de que se cuestionara (o no) explícitamente la existencia misma del sistema capitalista. Un criterio inverso se utilizó para delimitar la segunda categoría. Por su parte, en la primera categoría ubicamos los enfrentamientos en donde los objetivos explícitos cuestionaran aspectos parciales sin llegar a proponer una alternativa política y económica diferente a la puesta en práctica por el gobierno.

39 No nos parece pertinente subestimar este tipo de acciones, ya que como sostienen Izaguirre y Aristizabal (2002: 48) no sólo suelen expresar momentos particulares de confrontaciones más prolongadas, sino que además generalmente tienen por objeto delimitar los diferentes componentes de una fuerza y de su antagonista; aunque no dejan de ser modalidades de enfrentamiento que se encuentran en gran medida institucionalizadas y que se ajustan mayormente a las normas legales

40 En el caso del movimiento obrero estas variables presentaron valores considerablemente más bajos: 8,5\% y 3,6\% respectivamente.

41 En su gran mayoría, los casos que incluimos en esta variable fueron hechos en los se hizo uso de las distintas bombas de fabricación casera, tales como las "bombas molotov".

42 Durante 1971 el movimiento estudiantil consigue también articular sus campañas de movilización con las luchas de los trabajadores no docentes de la UNLP. En términos generales, el movimiento estudiantil tuvo mayores éxitos en forjar vínculos con los sectores más combativos y militantes de la clase obrera local. En particular, como señala Robles las "calles" platenses se transformaron en el escenario predilecto en el que se desarrollaba el encuentro "obrero-estudiantil” (Robles, 2011:36).

43 Entre otros, López Sánchez (2005) y Aranda Sánchez (2000) han destacado este aspecto para el caso del movimiento estudiantil en América Latina en general. Según Aranda Sánchez, en las sociedades latinoamericanas el movimiento 
Trabajos y Comunicaciones, 2da. Época, № 48, e066, julio-diciembre 2018. ISSN 2346-8971

estudiantil “...conlleva una orientación política en la medida que cuestiona y demanda el uso de recursos y condiciones manejadas por el Estado, ya sean reivindicaciones gremiales o cambios sociopolíticos." (Aranda Sánchez, 2000: 248).

44 Véase en el mismo sentido Millán (2011)

45 Tengamos en cuenta que en el caso de la UNLP, las agrupaciones estudiantiles consideraban al rector de la Universidad platense, Roque Gatti, como uno de los más capaces en llevar a cabo lo que se consideraba como el "participacionismo estudiantil". Las autoridades universitarias platenses nunca prohibieron la actividad de los centros, se pronunciaron públicamente contra algunos aspectos de la ley universitaria y la falta de presupuesto, además de manifestarse a favor de la salida institucional. 